\title{
Tabularia
}

\section{Le tabellionage normand : du sceau à la signature ? Pour une étude des signes de validation pendant le règne de Charles V (1364-1380)}

Norman Tabellionage: From the Seal to the Signature? For a Study of the Signs of Validation during the Reign of Charles V (1364-1380)

Norman Tabellionage: dal sigillo alla firma? Per uno studio dei segni di convalida durante il regno di Carlo V (1364-1380)

Die normannische „tabellionage“: Vom Siegel zur Unterschrift? Studie zu

Beglaubigungsmethoden unter Karl V (1364-1380)

\section{Claude Jeay}

\section{OpenEdition}

\section{Journals}

Édition électronique

URL : http://journals.openedition.org/tabularia/4796

DOI : 10.4000/tabularia.4796

ISSN : 1630-7364

Éditeur :

CRAHAM - Centre Michel de Boüard, Presses universitaires de Caen

\section{Référence électronique}

Claude Jeay, «Le tabellionage normand : du sceau à la signature? Pour une étude des signes de validation pendant le règne de Charles V (1364-1380) ", Tabularia [En ligne], Richesse du tabellionage normand au Moyen Âge, mis en ligne le 03 novembre 2020, consulté le 05 novembre 2020. URL http://journals.openedition.org/tabularia/4796 ; DOI : https://doi.org/10.4000/tabularia.4796

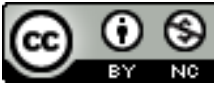

la revue Tabularia est mise à disposition selon les termes de la Licence Creative Commons Attribution - Pas d'Utilisation Commerciale 4.0 International. 

Le tabellionage normand: du sceau à la signature? Pour une étude des signes de validation pendant le règne de Charles V (1364-1380)

\author{
Norman Tabellionage: From the Seal to the Signature? \\ For a Study of the Signs of Validation \\ during the Reign of Charles V (1364-1380) \\ Norman Tabellionage: dal sigillo alla firma? \\ Per uno studio dei segni di convalida \\ durante il regno di Carlo V (1364-138o)
}

Die normannische „tabellionage“:

Vom Siegel zur Unterschrift? Studie zu

Beglaubigungsmethoden unter Karl V (1364-1380)

Claude JEAY

Directeur des archives départementales d'Ille-et-Vilaine -

1 rue Jacques-Léonard, 35000 Rennes

claude.jeay@gmail.com

Résumé:

La majorité des tabellions des juridictions royales en Normandie est incontestablement influencée par la chancellerie du roi de France lorsqu'il leur faut adopter un paraphe, alors que d'autres au contraire font preuve d'originalité. Dans tous les cas, le choix du paraphe n'est pas anodin, mais combine possibilités graphiques, marque d'appartenance et dimension symbolique. Ce foisonnement témoigne du dynamisme de la juridiction gracieuse du roi dans la province normande, preuve du rayonnement du pouvoir royal, dont les manifestations visibles se trouvent ainsi démultipliées.

Mots clés: seing manuel, quittance, paraphe, juridiction gracieuse, vicomté, formule de corroboration

\begin{abstract}
:
The majority of the tabellions of the royal jurisdictions in Normandy are undeniably influenced by the chancellery of the King of France, when they need to adopt an paraph, while others, on the contrary, are original. In any case, the choice of the paraph is not insignificant, but combines graphic possibilities, brand identity and symbolic dimension. This abundance reflects the dynamism of the king in the Norman province, proof of the influence of royal power, whose visible manifestations are thus multiplied.
\end{abstract}

Keywords: notarial mark, receipt, paraphs, non-contentious jurisdiction, viscounty, clause of corroboration

Tabularia «Études», «Richesse du tabellionage normand...», 2020, p. 1-27, 3 novembre 2020 URL: http://journals.openedition.org/tabularia/4796 | DOI: 10.4000/tabularia.4796 


\section{Riassunto:}

La maggior parte dei tabelloni delle giurisdizioni reali in Normandia è indubbiamente influenzata dalla cancelleria del re di Francia quando devono adottare una sigla, mentre altri, al contrario, mostrano originalità. In tutti i casi, la scelta del paraffo non è insignificante, ma unisce possibilità grafiche, un segno di appartenenza e una dimensione simbolica. Questa abbondanza testimonia il dinamismo della graziosa giurisdizione del re nella provincia normanna, prova dell'influenza del potere reale, le cui manifestazioni visibili si moltiplicano cosi.

Parole chiave: signum tabellionis, ricevuta, paraffo, giurisdizione non-contenziosa, viscontea, clausola di corroborazione

\section{Abstrakt:}

Die Mehrheit der „Tabellions" der königlichen Jurisdiktion in der Normandie ist unbestreitbar von der französischen königlichen Kanzlei beeinflusst, wenn sie etwa zur Paraphe eingereicht wurden, während andere im Gegensatz dazu im Original überliefert sind. In allen Fällen ist die Wahl der Paraphe keinesfalls unbedeutend. Die Zunahme bezeugt die Dynamik der unentgeltlichen königlichen Gerichtsbarkeit in der normannischen Provinz, Beweis für die Ausstrahlung der königlichen Macht, deren sichtbare Verkörperung sich um ein vielfaches steigerte.

Schlagworte: Handzeichen, Quittung, Paraphe, Unentgeltiche Gerichtsbarkeit, Vizegrafschaft, Beglaubigungsformeln

La présente étude fait suite à un premier travail mené en 2011 sur les seings manuels des tabellions normands des $\mathrm{XIV}^{\mathrm{e}}$ et $\mathrm{XV}^{\mathrm{e}}$ siècles ${ }^{1}$. Elle est cette fois consacrée exclusivement au règne de Charles $\mathrm{V}$, période pendant laquelle l'usage $\mathrm{du}$ paraphe est désormais bien établi en chancellerie, parmi les notaires et secrétaires du roi, ainsi que chez les officiers et autres agents de la couronne. C'est aussi sous les premiers Valois que les juridictions laïques sortent victorieuses de leur conflit ouvert avec le régime de l'officialité instauré par l'Église et que se développe le tabellionage, porté par le pouvoir royal et érigé en système. La numérisation des registres correspondants de la série des "Quittances et pièces diverses» de la Bibliothèque nationale de France, tous disponibles sur internet, a également compté dans ce choix ${ }^{2}$. Ces recueils rassemblent de nombreux documents, en majorité des quittances, qui concernent pour l'essentiel la Normandie. La précédente étude, qui embrassait deux siècles, se fondait, pour le règne

1. JEAY, 2011. L'ensemble des illustrations proposées dans la planche (voir annexe 1) sont des reproductions à la plume d'après les originaux. Il convient également de citer les travaux d'Isabelle Bretthauer et en particulier sa thèse de doctorat en histoire médiévale: Bretthauer, 2011a; Bretthauer, 2011b; Tabellionages au Moyen Âge en Normandie..., 2014, sans oublier BARABÉ, 1863 .

2. "Quittances et pièces diverses: mandements royaux, quittances, mémoires, comptes, etc., classés chronologiquement depuis Louis IX jusqu'à Louis XVI (1267-1783)» (Paris, BnF, ms fr. 2599226262). 
de Charles V, sur le dépouillement de trois de ces registres seulement ${ }^{3}$. C'est désormais l'ensemble des onze volumes qui a été dépouillé, ce qui représente un total de 2744 documents, dont un bon millier a été établi par les juridictions royales en Normandie, qu'il s'agisse des bailliages, vicomtés, comtés ou châtellenies (annexes 2 et 3$)^{4}$. Il est donc bien question de rouvrir le dossier, mais, en en resserrant les bornes chronologiques, de tenter d'offrir une vision plus fine, d'être davantage attentif aux petites différences, aux détails, aux particularités des paraphes, tous révélateurs finalement d'une pratique de l'écriture et plus largement de l'usage des signes de validation.

\section{Les tabellions normands, promoteurs du paraphe de la chancellerie royale}

Pendant le règne de Jean le Bon (1350-1364) et au début du règne de son fils Charles $\mathrm{V}$, la tendance est à la sobriété et les paraphes sont souvent réduits à de simples traits de soulignement éventuellement associés à une boucle finale. C'est ainsi que se présentent les seings manuels de Michel de Coutun (annexe $1, \mathrm{n}^{\circ} 1$ ), Eliot de Heauville (annexe $1, n^{\circ} 2$ ), Jehan la Chapenière (annexe $1, n^{\circ} 3$ ) ou encore Robert de Monfort, clerc tabellion juré à Falaise (annexe 1, no 4$)^{5}$. Dès 1364, le seing manuel de Denis Precestiour, clerc tabellion juré auprès de Guillaume Gautier, prêtre garde du sceau des obligations de la vicomté de Mortain (annexe 1, $\mathrm{n}^{\circ}{ }^{5}$ ), combine ces deux éléments en les faisant précéder d'un petit «n» également suivi d'une boucle, à l'origine abréviation de notaire ou notarius, puis simple signe graphique ${ }^{6}$. Johan Jehan, tabellion sous Renout Vautier, «clerc garde seel des obligations de la vicomté du chasteau de Vire» (annexe $1, \mathrm{n}^{\circ} 6$ ), associe ces mêmes éléments ${ }^{7}$ tout comme Laurent Descageux, qui est lui aussi actif dans cette juridiction (annexe $1, \mathrm{n}^{\circ} 7$ ). Il est frappant de comparer ces deux signatures qui par chance figurent sur une même quittance: c'est à se demander lequel a influencé l'autre, tant les similitudes entre les deux sont évidentes, que l'on

3. Paris, BnF, ms fr. 26006,26008 et 26010.

4. Paris, BnF, ms fr. 26006-26016. Certains documents ont toutefois dû être écartés en raison de leur état matériel (documents lacunaires, brûlés) ou parce que la qualité du microfilm et/ou de la numérisation ne permettait pas de lire tout ou partie des informations nécessaires à la présente étude. En revanche, quelques quittances établies aux confins de la Normandie, dans les actuels départements de l'Eure-et-Loir et des Yvelines, ont été prises en compte.

5. Michel de Coutun est le tabellion de Jehan le Boucher, garde du sceau des obligations de la vicomté de Bayeux. Il signe près d'une trentaine de quittances du 3 mai 1364 (Paris, BnF, ms fr. 26006, $n^{\circ}$ 9) au 27 août 1374 (Paris, BnF, ms fr. 26012, $\mathrm{n}^{\circ}$ 1519). Eliot de Heauville, clerc tabellion de la vicomté de Valognes, appose son seing manuel sur une unique quittance (Paris, BnF, ms fr. 26006, $\mathrm{n}^{\circ} 168$, 14 mai 1365). Jehan la Chapenière est également au service de Jehan le Boucher et signe une seule quittance le 3 novembre 1365 (Paris, BnF, ms fr. 26006, $\mathrm{n}^{\circ}$ 225). Robert de Montfort signe 24 quittances du $1^{\text {er }}$ octobre 1364 (Paris, BnF, ms fr. 26006, $n^{\circ} 76$ ) au 13 janvier 1376 (Paris, BnF, ms fr. 26013, $\left.\mathrm{n}^{\circ} 1757\right)$.

6. Paris, BnF, ms fr. 26006, $\mathrm{n}^{\circ} 8$, quittance du 26 avril 1364.

7. 11 quittances signées par le tabellion Johan Jehan entre le 31 mai 1364 (Paris, BnF, ms fr. 260o6, $\mathrm{n}^{\circ} 16$ ) et le 20 avril 1377 (Paris, BnF, ms fr. 26013, $\mathrm{n}^{\circ}$ 1908). 
considère le paraphe proprement dit ou l'écriture ${ }^{8}$. Raoul Païen, tabellion de la vicomté de Bayeux, opte lui aussi dès 1364 pour un encadrement sommaire de son patronyme en combinant boucles, traits de plume horizontaux et verticaux avec la lettre « $\mathrm{n}$ » (annexe $\left.1, \mathrm{n}^{\circ} 8\right)^{9}$, à l'instar de Pierre de Biaurain ${ }^{10}$ ou de Bertin Basille ${ }^{11}$. D'autres tabellions ajoutent à leur seing manuel des points pour agrémenter la composition d'ensemble; c'est le cas de Perrin Trennefer (annexe 1, $\mathrm{n}^{\mathrm{o}}$ 9) ${ }^{12}$, ou encore Jehan Regnier ${ }^{13}$ et Pierre Laingnel ${ }^{14}$, qui s'inscrivent dans cette mouvance. Le tabellion d'Exmes, Jehan Basset, imagine un paraphe qui associe plusieurs boucles et triangles, composition assez élaborée mais au rendu finalement plutôt dépouillé ${ }^{15}$. Cette réalisation préfigure toutefois, comme les précédentes, le célèbre type de chancellerie, qui s'impose peu à peu en Normandie.

Toutes ces signatures sont somme toute largement inspirées de celles de la chancellerie royale, telles que les dessinent les notaires et secrétaires des rois Jean le Bon et Charles V, même si les tabellions se contentent dans la plupart des cas de n'en retenir que l'idée générale ou d'adopter plus particulièrement un seul motif ou élément. C'est pourquoi, à mesure qu'on avance dans le temps (certains tabellions signent sur de longues périodes) se creuse un écart entre la pratique promue par la chancellerie royale et les paraphes de ces tabellions, rendant ainsi anachroniques leurs créations graphiques pour la seconde partie $\mathrm{du}$ règne de Charles V. En voici tous les auteurs, soit une douzaine en tout, ce qui est peu rapporté au nombre total de signataires ${ }^{16}$ : Jehan le Barbey (1369) (annexe 1, $\mathrm{n}^{\circ}$ 10), Symon Baudet et Jehan l'Évesque (1370), Thomas Ernoul (1371), Enguerran Prudomme (1372), Érart Gourbaut (1374), Guillaume Gillain

8. Paris, BnF, ms fr. 26007, $\mathrm{n}^{\circ} 413,7$ octobre 1367. Quittance passée sous «Nicole l'Estassel prestre garde du seel des obligacions de la viconté du chasteau de Vire».

9. Raoul Païen exerce sous les ordres de Jehan le Boucher, garde du sceau des obligations de la vicomté. Il signe au moins à partir de 1364 (Paris, $\mathrm{BnF}, \mathrm{ms}$ fr. 26006, $\mathrm{n}^{\circ} 107,13$ novembre 1364) et jusqu'au 8 décembre 1368 (Paris, BnF, ms fr. 26008, $n^{\circ} 600$ ), soit 17 documents.

10. Tabellion de Jehan le Roy, "garde du seel dez obligacions de la viconté d'Arches», il signe sept quittances entre le 8 décembre 1367 (Paris, BnF, ms fr. 26007, $n^{\circ} 438$ ) et le 7 mai 1368 (Paris, BnF, ms fr. 26008, ${ }^{\circ} 500$ ).

11. Tabellion de la vicomté du Pont-de-l'Arche (Paris, BnF, ms fr. 26007, $\mathrm{n}^{\circ}$ 462, quittance du 28 janvier 1368).

12. Tabellion de Jehan Lenglos, garde du sceau des obligations de la vicomté de Valognes (Paris, BnF, ms fr. 26007, $\mathrm{n}^{\circ} 308$, quittance du 11 septembre 1366 ).

13. Tabellion auprès du vicomte de Pont-de-l'Arche (Paris, BnF, ms fr. 26006, $\mathrm{n}^{\circ}$ 154-155, deux quittances du 10 avril 1365).

14. Tabellion sous Raoul Rouillart, garde du sceau des obligations de la vicomté de Caen, Pierre Laingnel signe 16 documents entre le 12 octobre 1366 (Paris, BnF, ms fr. 26007, $\mathrm{n}^{\mathrm{o}} 315$ ) et le 24 septembre 1368 (Paris, BnF, ms fr. 26008, $n^{\circ} 578$ ).

15. Il exerce pour Jehan le Coutelier, garde du sceau des obligations de la vicomté de Falaise. Première signature: Paris, BnF, ms fr. $26008, \mathrm{n}^{\circ} 552,30$ août 1368 ; il signe à trois autres reprises (Paris, BnF, ms fr. 26009, $\mathrm{n}^{\circ} 891,28$ avril 1370 et $\mathrm{n}^{\circ}$ 1031, 12 mai 1370; ms fr. 26010, $\mathrm{n}^{\circ} 1148$, 10 mars 1370).

16. La date indiquée entre parenthèses est celle de la première occurrence de leur signature, dont la cote est indiquée dans la note suivante. La plupart d'entre eux ont signé d'autres quittances par la suite. 
dont le paraphe est réduit à sa plus simple expression (1376), Jehan Gervaise et Johan de Beaureperre (1377), Robert de Bistrebec et Michel Bourdon (1378), Jehan de la Tennereur (1379), enfin Guillaume Enguelos (1380) ${ }^{17}$.

La plupart des tabellions assimilent toutefois le modèle dominant qu'ils déclinent à la perfection, à l'image de Pierre le Clerc (annexe 1, $\mathrm{n}^{\circ} 11$ ), Thomas Pélichon ou encore Jehannin Bonnin l'Aisné qui, dès 1364-1365, associent avec bonheur toutes les composantes du paraphe décrites plus haut tout en tirant profit d'une grande verticale dont ils font autant que faire se peut l'initiale de leur nom de baptême et à partir de laquelle se déroule ensuite le patronyme. Ce type de chancellerie, développé par les notaires et secrétaires des rois Jean le Bon puis Charles V, est repris par tous les officiers royaux et donc par les tabellions et les clercs des juridictions du souverain, acteurs essentiels de cette promotion sur le territoire et au plus près de la population. Nombreux sont ainsi les tabellions qui intègrent, reprennent, adaptent ce parangon, offrant des réalisations de plus en plus abouties. Le paraphe dit «de chancellerie» coexiste avec les occurrences plus sommaires décrites ci-dessus puisqu'il apparait dès 1364 pour s'imposer rapidement, à partir de 1368-1369. Les praticiens de l'écrit qui se mettent à exercer dans une juridiction royale sont par conséquent de plus en plus nombreux à adopter l'usage en cours, de sorte que la pratique s'est imposée naturellement bien avant la fin du règne de Charles V. Les tabellions s'emparent du paraphe en manière d'encadrement sur trois côtés, le trait de soulignement et les deux verticales de part et d'autre, démultiplient les boucles et agrémentent la structure d'ornements, ces petits « $\mathrm{n}$ » et des points, pour rehausser et animer la composition graphique - au point qu'il serait difficile dans bien des cas de distinguer la signature d'un secrétaire de la chancellerie royale, de celle d'un tabellion normand contemporain ${ }^{18}$.

17. Jehan le Barbé, tabellion de la vicomté de Bayeux (Paris, BnF, ms fr. 26008, $\mathrm{n}^{\circ} 699,22$ juin 1369); Symon Baudet, tabellion de la châtellenie de Gournay (Paris, BnF, ms fr. 26009, ${ }^{\circ}$ 929, 8 juillet 1370); Jehan l'Évesque, tabellion de la vicomté de Bayeux (Paris, BnF, ms fr. 26009, $\mathrm{n}^{\circ}$ 951, 2 septembre 1370); Thomas Ernoul, tabellion de la vicomté du Pont-de-l'Arche (Paris, BnF, $\mathrm{ms}$ fr. $26010, \mathrm{n}^{\circ} 1162,1^{\mathrm{er}}$ avril 1371 ); Enguerran Prudomme, tabellion de la vicomté d'Auge (Paris, $\mathrm{BnF}, \mathrm{ms}$ fr. $26011, \mathrm{n}^{\circ}{ }_{1313}$, quantième et mois non précisés, 1372); Érart Gourbaut, tabellion de la châtellenie de Gournay (Paris, BnF, ms fr. 26012, $\mathrm{n}^{\circ}$ 1542, 12 novembre 1374); Guillaume Gillain, tabellion de la vicomté d'Orbec au siège de Chambrais (Paris, BnF, ms fr. 26013, $\mathrm{n}^{\circ} 1805$, 13 août 1376); Jehan Gervaise, clerc juré à la vicomté de Bayeux (Paris, BnF, ms fr. 26014, $\mathrm{n}^{\circ}$ 1962, 8 juillet 1377); Johan de Beaureperre, tabellion juré de la vicomté d'Avranches (Paris, BnF, ms fr. 26014, $\mathrm{n}^{\circ}$ 2033, 15 octobre 1377); Robert de Bistrebec, tabellion de la vicomté d'Auge au siège de Dozulé (Paris, BnF, ms fr. 26o15, $\mathrm{n}^{\circ} 2249,13$ août 1378); Michel Bourdon, tabellion de la vicomté de Caudebec (Paris, BnF, ms fr. 26015, $\mathrm{n}^{\circ}$ 2320, 9 novembre 1378); Jehan de la Tennereur, tabellion de la châtellenie d'Anet, dans l'actuel département d'Eure-etLoir (Paris, BnF, ms fr. 26015, $n^{\circ}$ 2321, 9 novembre 1378); Guillaume Enguelos, tabellion de la vicomté de Longueville (Paris, BnF, ms fr. 26016, $\mathrm{n}^{\circ}$ 2675, 4 avril 1380). Pour chaque tabellion il est donné dans la présente note une signature à titre d'exemple. Certains signent plusieurs fois: le tableau en annexe indique pour chaque tabellion le nombre d'occurrences et leurs dates extrêmes.

18. Pour la liste des tabellions normands étudiés dans cet article, le lieu, les dates d'exercice et les cotes extrêmes de leurs seings manuels, voir l'annexe 5 . 
Si dans l'ensemble les tabellions, bons élèves, assimilent le modèle de chancellerie, l'adoption d'un paraphe ne se limite pas à un exercice imposé, même si certains éprouvent manifestement un peu plus de difficulté à obtenir un résultat conforme, tel Robert Postel (annexe 1, $\mathrm{n}^{\circ} 12$ ), tabellion de la vicomté de Pont-de-l'Arche, qui produit un ensemble un peu fruste, approximatif; mais force est de constater, en fin de compte, que tout y est ${ }^{19}$. Guiot Caperon imagine une composition graphique un peu déséquilibrée, même $s^{\prime}$ il a parfaitement assimilé le modèle de référence ${ }^{20}$. Quelques tabellions sont en revanche de véritables précurseurs, qui multiplient les boucles et les combinaisons, plus travaillées, voire véritablement complexes, réalisant des paraphes qui seront à la mode à la chancellerie de Charles VI quelques années plus tard. Richart Garmont, Guillaume Troqueel, Guillaume le Barbey, Jehan du Rognon, Jehan des Wys, Richart le Moyne, Jehan Bonnin et Thomas Amador en font partie ${ }^{21}$. Au total, les tabellions sont des promoteurs efficaces de l'autorité royale, qui se manifeste concrètement par la diffusion du paraphe caractéristique inventé par les notaires et secrétaires du roi et repris par tous les officiers de la Couronne. Le respect du modèle n'exclut pas pour autant une certaine inventivité.

\section{Le paraphe des tabellions: un modèle normand?}

L'adoption du paraphe mis au goût du jour par la chancellerie de Jean le Bon et surtout Charles V offre une multitude de possibilités, issues de la combinaison de ses différents éléments constitutifs: lignes verticales et horizontales, boucles, triangles, ornements (petits « $\mathrm{n}$ » et points). Il en résulte autant de créations originales qui toutes suggèrent le modèle initial tout en se démarquant les unes des autres. L'initiale du nom de baptême permet de distinguer à coup sûr les signatures de tabellions dotés du même patronyme; les différences parfois subtiles d'un paraphe à l'autre offriraient même la possibilité d'attribuer sans risque d'erreur les signatures de tabellions dont l'écriture serait strictement

19. Paris, BnF, ms fr. 26014, $n^{\circ} 1941$, quittance du 7 juin 1377.

20. Paris, BnF, ms fr. 26015, $\mathrm{n}^{\circ} 2438$, quittance du 6 mars 1379

21. Richard Garmont (10 occurrences entre le 6 octobre 1367, Paris, BnF, ms fr. $26007, \mathrm{n}^{\circ} 410$ et le 26 juillet 1378, Paris, BnF, ms fr. 26015, $n^{\circ}$ 2233); Guillaume Troqueel, clerc à la châtellenie des Andelys ( 8 occurrences entre le $1^{\text {er }}$ avril 1371, Paris, BnF, ms fr. 26010, $\mathrm{n}^{\mathrm{o}} 1161$ et le 25 janvier 1378 , Paris, BnF, ms fr. 26014, $\mathrm{n}^{\circ}$ 2108); Guillaume le Barbey, tabellion juré de la vicomté de Bayeux (2 occurrences, 17 novembre 1375, Paris, BnF, ms fr. 26012, $n^{\circ} 1718$ et 27 juin 1379, Paris, BnF, ms fr. 26016, $\mathrm{n}^{\circ}$ 2515); Jehan du Rognon, clerc de Guillaume Bréart, tabellion de la vicomté de Montivilliers (2 signatures: 30 août 1378, Paris, BnF, ms fr. 26015, $\mathrm{n}^{\circ} 2269$ et 23 février 1379, Paris, $\mathrm{BnF}, \mathrm{ms}$ fr. $26015, \mathrm{n}^{\circ} 2425$ ); Jehan de Wys, tabellion juré de la vicomté de Rouen (21 occurrences entre le 4 septembre 1379 , Paris, BnF, ms fr. $26016, n^{\circ} 2566$ et le 2 août 1380 , Paris, BnF, ms fr. 26016, $\mathrm{n}^{\circ}$ 2723); Richart le Moyne, tabellion juré de la vicomté de Vire (2 signatures du 22 novembre 1379, Paris, BnF, ms fr. 26016, $\mathrm{n}^{\circ}$ 2602-2603); Jehan Bonnin, tabellion de la châtellenie de Mantes (3 et 4 février 1380, Paris, BnF, ms fr. 26016, $\mathrm{n}^{\circ}$ 2640-2641) et Thomas Amador, tabellion de la vicomté de Pont-Authou au siège de Lisieux (Paris, BnF, ms fr. 26016, $\mathrm{n}^{\circ}$ 2744, 15 septembre 1380 ). 
identique (initiale du prénom et patronymes similaires). Les signatures de Manessier, Rogier et Guiot Caperon constituent à ce titre un très bon exemple (annexe 1, $\left.\mathrm{n}^{\mathrm{o}} 13-15\right)^{22}$.

Nombreux sont par ailleurs les tabellions qui font preuve d'imagination et suggèrent des variantes subtiles et, de fait, inédites. Martin Lignis, tabellion de la vicomté d'Avranches et Guillaume Lemestre, son clerc, signent tous les deux de la même façon, faisant suivre leur patronyme d'une combinaison assez originale obtenue à partir des composantes essentielles du paraphe de chancellerie (annexe 1, $\left.\mathrm{n}^{\mathrm{o}} 16-17\right)^{23}$. Jehan Floury, tabellion de la vicomté de Beaumont-leRoger referme les boucles sur elles-mêmes pour former à chaque fois un petit cercle dont il orne le centre d'un point (annexe $\left.1, \mathrm{n}^{\circ} 18\right)^{24}$. Les paraphes proposés par Guillaume le Prevost, Michiel Jaques, Denis Malesche, Robert le Marchant ou encore Guerart Meslin se distinguent également des réalisations parfaites mais plus convenues de nombre de leurs contemporains ${ }^{25}$. Tous jouent avec les formes géométriques, cercles, triangles, torsades, formes pleines ou vides, hachures, points... pour obtenir des résultats inattendus. Guillaume Bréart met en valeur son patronyme en l'enserrant dans un encadrement complexe (annexe 1, $\left.\mathrm{n}^{\circ} 19\right)^{26}$; Henry Neel, tabellion à la vicomté de Breteuil, s'affranchit de tout modèle pour inscrire très librement prénom et nom dans un cartouche aux coins sommairement ornés de lignes ondulées (annexe $1, \mathrm{n}^{\circ} 20{ }^{27}$. Le tabellion auprès du garde du sceau des obligations de la vicomté d'Évreux, Raoul Paillele, utilise à trois reprises le motif bien connu du triangle combiné à la boucle, ce qui suffit à donner un côté original à son paraphe ${ }^{28}$. Guillaume Lenglois, quant à lui, enrichit l'encadrement classique de nombreux points et petits ronds pour se distinguer ${ }^{29}$, alors que Gilles le Peletier, «prestre tabellion nommé et establi en ladite viconté [de Pont-Authou]», tente une synthèse en associant une série

22. Manessier Caperon, «clerc tabellion juré des lettres obligatoires de madame la royne Blanche en ladite viconté [de Noef Chastel] » (Paris, BnF, ms fr. 26014, n 1946, 16 juin 1377; Rogier Caperon, "clerc tabellion juré des lettres et obligacions dudit lieu [de Dieppe] » [Paris, BnF, ms fr. 26015, $\mathrm{n}^{\circ} 2368,29$ décembre 1378; $\mathrm{n}^{\circ} 2403,13$ janvier 1379; $\mathrm{n}^{\circ}$ 2426, 23 février 1379]; Guiot Caperon, tabellion de la vicomté de Coutances au siège de Montebourg [Paris, BnF, ms fr. 26015, $\mathrm{n}^{\circ} 2438$, 6 mars 1379]).

23. Paris, BnF, ms fr. 26015, $\mathrm{n}^{\circ} 2323$, quittance du 11 novembre 1378 .

24. 6 occurrences entre le 20 avril 1368 (Paris, BnF, ms fr. 260o8, $\mathrm{n}^{\circ} 491$ ) et le 20 avril 1378 (Paris, BnF, ms fr. 26014, $n^{\circ} 2172$ ).

25. Guillaume le Prévost, tabellion auprès du sénéchal de Lisieux ( $1^{\text {er }}$ octobre 1368, Paris, BnF, ms fr. 26008, $\mathrm{n}^{\circ}$ 582). Michiel Jaque, tabellion de la vicomté de Bernay (18 et 22 mai 1375, Paris, BnF, ms fr. 26012, $\mathrm{n}^{\circ} 1616$ et 1618). Denis Malesche, tabellion juré de la vicomté de Breteuil (15 décembre 1376, Paris, BnF, ms fr. 26013, $\mathrm{n}^{\circ}$ 1801). Robert le Marchant, tabellion de la vicomté d'Auge au siège de Pont-l'Évêque (15 mars 1378, Paris, BnF, ms fr. 26014, nº 2140). Guerart Meslin, tabellion de la vicomté de Montivilliers (10 novembre 1378, Paris, BnF, ms fr. 26015, $\mathrm{n}^{\circ} 2322$ ).

26. Clerc de la vicomté de Montivilliers au siège de Harfleur: 6 signatures entre le 2 août 1377 (Paris, BnF, ms fr. 26014, $\mathrm{n}^{\circ}$ 1983) et le 26 juin 1380 (Paris, BnF, ms fr. 26016, $\mathrm{n}^{\circ} 2700$ ).

27. Signatures des 12 et 17 janvier 1379 (Paris, BnF, ms fr. 26015, $n^{\circ} 2394$ et 2401).

28. Paris, BnF, ms fr. 26015, $\mathrm{n}^{\circ} 2399$, quittance du 15 janvier 1379.

29. Tabellion juré de la châtellenie de Nogent-le-Roi (18 et 21 mars 1379, Paris, BnF, ms fr. 26015, $n^{\circ} 2447$ et 2449). 
de boucles à un simple cartouche ${ }^{30}$. Plus dépouillée encore est la signature de Colin Ment, tabellion de la vicomté d'Auge, qui se contente de faire figurer son seul patronyme inscrit en lettres de petit module sans lui associer de paraphe (annexe 1, $\left.\mathrm{n}^{\circ} 21\right)^{31}$. La signature d'Esber le Terrier s'étire en longueur, combinant écriture et éléments graphiques; parmi ces derniers, certains sont bien connus et rappellent les paraphes des notaires et secrétaires des premiers Valois, Jean le Bon et surtout Philippe VI, l'élément initial évoquant vaguement une fleur stylisée (trois pétales et une tige) et qui apparaît à la chancellerie royale sous Charles VI étant quant à lui tout à fait dans l'air du temps ${ }^{32}$. Dans l'ensemble, les tabellions de Normandie assimilent très rapidement le paraphe inventé par la chancellerie du roi de France et promu à leur tour par les officiers du souverain dans le royaume. Pour autant, un second groupe se détache, qui a bien intégré les particularités graphiques du modèle comme sa portée symbolique mais en joue, détourne les codes et propose des réalisations originales qui vont jusqu'à s'affranchir complètement du type de chancellerie. Mais il ne s'agit pas de particularités propres aux tabellions normands. Ailleurs aussi les praticiens de l'écrit au service de la couronne se partagent entre ceux qui reproduisent le paraphe type de la chancellerie royale et ceux, souvent minoritaires, qui font preuve d'imagination. Cet usage est loin d'être anecdotique et circonscrit à quelques cas isolés; l'exemple normand est à ce titre tout à fait représentatif. Le foisonnement graphique qui en résulte témoigne de l'essor et de la vitalité de la juridiction gracieuse royale en Normandie pendant le règne de Charles V.

L'adoption majoritaire du paraphe de chancellerie et la diversité des pratiques observées par ailleurs partagent cependant certaines caractéristiques communes. Toute signature de tabellion comprend forcément une partie écrite, composée presque toujours du patronyme souvent précédé de l'initiale du nom de baptême. Peu nombreux sont ceux qui signent uniquement de leur prénom, qui plus est sous forme abrégée, comme Laurens Chapillart, tabellion auprès de Philippe de Mangueville, garde du sceau des obligations de la vicomté de Rouen, qui signe "Laur ${ }^{33}$. Le cas le plus intéressant est celui de Gieffroy Morice, qui a utilisé des signatures différentes dans l'exercice de ses fonctions. Tabellion de la vicomté de Caen auprès du garde du sceau des obligations Raoul Rouillart, il adopte un paraphe d'une évidente perfection formelle en sorte qu'il pourrait tout à fait passer pour celui d'un notaire et secrétaire du roi contemporain. Sur une quittance du 15 décembre 1364, il signe "Gieffroy" (annexe 1, n $\left.{ }^{\circ} 22 \mathrm{a}\right)^{34}$. Sur une autre, il appose trois signatures différentes, toutes construites à partir d'un paraphe identique: il signe à nouveau de son prénom, puis «G. Morice aud.», ou encore " aud. Gieffroy»

30. Paris, $\mathrm{BnF}, \mathrm{ms}$ fr. $26007, \mathrm{n}^{\circ} 381,15$ mai 1367 .

31. Paris, BnF, ms fr. $26008, n^{\circ} 583$ et 586 , respectivement 3 et 6 octobre 1368 .

32. Tabellion de la vicomté d'Orbec, 25 occurrences entre le $1^{\mathrm{er}}$ avril 1373 (Paris, BnF, ms fr. 26o11, $\mathrm{n}^{\circ}$ 1382) et le 18 février 1377 (Paris, BnF, ms fr. 26013, $\mathrm{n}^{\circ} 1860$ ).

33. 10 signatures du 12 avril 1369 (Paris, BnF, ms fr. 26008, $\mathrm{n}^{\circ} 670$ ) et le 17 août 1371 (Paris, BnF, $\mathrm{ms}$ fr. 26010, $\mathrm{n}^{\circ}$ 1236).

34. Paris, BnF, ms fr. 26006, $\mathrm{n}^{\circ} 116$. 
(annexe 1, $\mathrm{n}^{\circ}$ 22c) - et enfin simplement «aud.» ${ }^{35}$. Il faut certainement entendre "aud.» pour "audivit», ce qui reviendrait à reconnaître la fonction de témoin du tabellion, physiquement présent lors de l'élaboration de l'acte, la rédaction de la quittance entre les parties - ou à tout le moins pendant l'audience à laquelle fait suite la mise au net du document ${ }^{36}$. Devenu vicomte de Vire à partir de 1368 , Gieffroy Morice renonce à la signature (il ne confie pas non plus la plume à un clerc) et valide une quittance de son seul sceau: «En tesmoing de ce nous avons mis a ces lettres le seel des obligacions de la dite viconté ${ }^{37}$. Quelques années plus tard, occupant toujours les mêmes fonctions, il fait un compromis - ou, c'est selon, la synthèse des signatures précédentes - et signe cette fois " $G$. Morice " (annexe 1, $\left.\mathrm{n}^{\mathrm{o}} 22 \mathrm{~b}\right)^{38}$. On le voit, la pratique n'est pas encore figée, tant s'en faut, et le tabellion (puis vicomte) hésite entre les différentes possibilités qui s'offrent à lui. Rien ne permet d'assigner tel ou tel paraphe à un usage particulier, le tabellion employant indifféremment l'un ou l'autre. Robert Bérengier, lui aussi tabellion à Caen sous les ordres de Raoul Rouillart et qui succède justement à Gieffroy Morice à partir de 1372, commence par signer sous forme abrégée «R. B. aud.» (annexe 1, no $23 a)^{39}$, puis inscrit tantôt son seul patronyme ${ }^{40}$, tantôt le fait suivre de la mention «aud.» (annexe $\left.1, \mathrm{n}^{0} 23 \mathrm{~b}\right)^{41}$. Ces usages mouvants, ces réalisations complexes, semblent propres à la vicomté de Caen au tournant des années 1368-1370. Dans leur immense majorité, les tabellions normands adoptent une signature une fois pour toutes, quelles que soient la typologie documentaire et la juridiction pour laquelle ils officient; ils s'y tiennent par la suite même s'ils évoluent dans leurs fonctions (un clerc devenu tabellion, un tabellion promu vicomte).

Autre point commun entre la plupart des signatures de tabellions normands, l'usage de ce petit « $\mathrm{n}$ » dont il a déjà été question plus haut. Il s'agit d'un signe très présent dans la mise en forme des actes de la chancellerie royale, au commencement ou pour séparer les différentes parties du discours, par exemple de part et d'autre de la formule de corroboration, de l'eschatocole, ou encore dans les formules de commandement - et plus largement les mentions hors teneur. Les tabellions s'approprient cette lettre qui devient non signifiante, simple ornement et composante attendue du paraphe. Par-delà cet usage graphique réservé à la signature, les tabellions émaillent aussi leurs actes (en particulier les quittances, mais également d'autres documents) de ces mêmes petits " $\mathrm{n}$ ", à l'instar de notaires et secrétaires du roi sur les chartes ou les mandements.

35. Paris, BnF, ms fr. $26006, \mathrm{n}^{\circ} 164,29$ avril 1365. Ces signatures se retrouvent également sur les actes suivants: Paris, BnF, ms fr. 26006, $n^{\circ} 183$, quittance du 15 juillet $1365 ; n^{\circ} 229$, quittance du 7 novembre $1365 ; \mathrm{ms}$ fr. $26007, \mathrm{n}^{\circ} 327$, quittance du 22 novembre 1366.

36. La présence du tabellion, praticien de l'écrit mais aussi témoin privilégié, est rendue dans les quittances par la formule "par devant», immédiatement suivie des prénom, nom et qualité du tabellion.

37. Paris, BnF, ms fr. $26008, n^{\circ} 549,27$ août 1368 .

38. «Donné à Caen soubz le seel de ladite viconté» (Paris, BnF, ms fr. 26010, $n^{\circ}$ 1202, quittance du 25 mai 1371).

39. Paris, BnF, ms fr. 26011, $\mathrm{n}^{\circ} 1350$ (17 novembre 1372 ); $\mathrm{n}^{\circ} 1436$ et 1437 (2 décembre 1373 ).

40. Par exemple Paris, BnF, ms fr. 26011, $\mathrm{n}^{\circ}$ 1442, quittance du 23 décembre 1373.

41. À titre d'exemple, voir Paris, BnF, ms fr. 26014, $\mathrm{n}^{\circ}$ 2038, 24 octobre 1377. 
Ces particularités graphiques largement partagées créent une communauté des praticiens de l'écrit qui usent des mêmes codes pour affirmer leurs prérogatives et, par-delà, imposer l'autorité royale. L'étude de l'écriture, et plus généralement des caractères externes des actes du corpus montre une grande diversité de la production, plus ou moins solennelle, plus ou moins soignée en fonction des juridictions et/ou des praticiens de l'écrit qui y exercent.

\section{Du sceau à la signature}

La présente étude porte sur 1042 documents, pour l'essentiel des quittances, provenant parfois en nombre de telle ou telle juridiction en sorte qu' un nombre important de pièces - parfois plusieurs dizaines - sont signées par un même tabellion (voir tableau infra ${ }^{42}$. Tous les documents sont validés par le sceau de l'autorité qui a produit le document, et le sceau est systématiquement annoncé dans la formule de corroboration. Les données collectées permettent d'établir la proportion de documents signés par année, mais celle-ci est peu significative: le nombre de documents varie beaucoup d'une année sur l'autre, et pour une même année, certains tabellions signent parfois de nombreuses pièces, en sorte que le pourcentage obtenu est peu significatif (graphique). Il n'en reste pas moins que ces statistiques, mises en perspectives dans la durée et en comparaison des règnes de Jean le Bon et Charles VI, révéleraient à n'en pas douter que les tabellions sont de plus en plus nombreux à faire usage d'un seing manuel. La moyenne de documents signés de 1364 à 1380 est, elle, intéressante, celle-ci met en évidence que les trois-quarts des quittances sont signées (795 sur 1042, soit 75,46\%).

\begin{tabular}{|l|r|r|r|}
\hline Année & \multicolumn{2}{|l|}{$\begin{array}{l}\text { Nombre de } \\
\text { documents }\end{array}$} & \multicolumn{2}{|l|}{$\begin{array}{l}\text { Nombre de } \\
\text { signatures }\end{array}$} & \multicolumn{2}{l|}{$\begin{array}{l}\text { Proportion de } \\
\text { documents signés (\%) }\end{array}$} \\
\hline 1364 & 41 & 27 & 65,85 \\
\hline 1365 & 46 & 27 & 58,7 \\
\hline 1366 & 30 & 21 & 70 \\
\hline 1367 & 44 & 32 & 72,72 \\
\hline 1368 & 93 & 87 & 93,5 \\
\hline 1369 & 102 & 62 & 60,78 \\
\hline 1370 & 73 & 61 & 83,56 \\
\hline
\end{tabular}

42. Voici les principaux tabellions signataires: Nicolas le Mestre (vicomté de Rouen, 48), Thomas Pélichon (vicomté de Caen, 44), Jehan Bacon (vicomté de Rouen, 32), Robert Bérengier (vicomté de Caen, 28), Michel de Coutun (vicomté de Bayeux, 27), Esber le Terrier (vicomté d'Orbec, 25), Robert de Monfort (vicomté de Falaise, 24), Jehan Bonnin l'Aîné (châtellenie de Mantes, 23), Jehan Wys et Jehan Waart (vicomtés de Rouen et d'Arches, 21). 


\begin{tabular}{|c|r|r|r|}
\hline 1371 & 69 & 54 & 78,26 \\
\hline 1372 & 36 & 32 & 88,89 \\
\hline 1373 & 38 & 29 & 76,32 \\
\hline 1374 & 46 & 44 & 95,65 \\
\hline 1375 & 68 & 57 & 83,82 \\
\hline 1376 & 18 & 11 & 61,11 \\
\hline 1377 & 65 & 53 & 81,54 \\
\hline 1378 & 129 & 92 & 71,32 \\
\hline 1379 & 108 & 83 & 76,85 \\
\hline 1380 & 36 & 23 & 63,89 \\
\hline Total & 1042 & 795 & Moyenne: 75,46 \\
\hline
\end{tabular}

Proportion de quittances signées établies par les tabellions

La première mention d'une signature dans une formule de corroboration apparaît sur une quittance du 28 mars 1368 passée par «Jehan de Berville, bourgois de Rouen, lieutenant de Johan d'Orlieux conseiller du roy et receveur pour toute la Normendie sur les aides» et qui se présente comme suit: «Tesmoing mon seel avec mon signe mis a ceste cedule ${ }^{43}$. Une autre quittance, passée cette fois devant Guillaume Godier, «prestre garde du seel des obligacions de la chastellenie de Lyons», porte la formule: «En tesmoing de ce nous a la relacion et signet dudit commis avons seellé ces lettres du seel des dites obligacions ${ }^{44}$. Or, ni marque autographe ni cachet (le terme de "signet " pourrait renvoyer à l'un ou à l'autre) ne figure au bas du document, exclusivement scellé du sceau de la juridiction. Pour autant, il s'agit de la deuxième mention rencontrée. L'année suivante, Jehan Vouchis, receveur général des aides de Lisieux, Sées, Bayeux, Coutances et Avranches, valide une quittance au moyen de son sceau et de son seing manuel: «En tesmoing de ce j'ay signé ceste lettre de ma main et seellee de mon seel» ${ }^{45}$. La signature figure bien cette fois sur le document. Le clerc tabellion juré de Gisors, Guillaume de Longchamp, également "garde du seel aux obligacions de la chastellenie dudit lieu de par notre seigneur le roy", prend lui aussi la plume aux mêmes fins («En tesmoing de ce nous avons seellé ces lettres du seel de ladite chastellenie avec notre signet») et le «signet» renvoie explicitement à la signature visible dans la marge inférieure ${ }^{46}$. C'est une formule

43. Paris, BnF, ms fr. $26007, \mathrm{n}^{\circ} 482$.

44. Paris, $\mathrm{BnF}, \mathrm{ms}$ fr. $26008, \mathrm{n}^{\circ} 688$, quittance du 14 mai 1369. Le «commis» dont il est question est "Guillemin Pillon clerc a ce commis de par nous si comme il nous a tesmoigné».

45. Paris, BnF, ms fr. 26009, $\mathrm{n}^{\circ} 946,19$ août 1370.

46. Paris, BnF, ms fr. 26010, $\mathrm{n}^{\circ} 1143,7$ mars 1371. 
presque identique, quoiqu'un peu plus ramassée qui est apposée sur un acte donné par Raoul Campion, «general visiteur et receveur es dioceses de Lisieux, Sées Bayeux, Coustances et Avranches sur le fait des aides» («Tesmoing mon seel avec mon signe mis a ceste quittance» $)^{47}$. Richard le Moigne, prêtre et garde du sceau de la châtellenie de Lionz [Lyons], adopte ce nouvel usage ( En tesmoing de ce nous avons seellé ceste presente quittance dudit seel et notre signet $»)^{48}$, tout comme Guillaume Johan, «procureur de mestre Estienne Molnier, chappellain de la chappelle de Saint Julian de Gournay » ${ }^{49}$. Jacques le Boucher, prévôt de Harfleur, préfère «signe manuel» à signet ${ }^{50}$, expression également reprise en 1377 par le vicomte du Pont-de-l'Arche, Jean Auber ${ }^{51}$, le "grenetier et contrerolleur du grenier a seel establi a Harefleu », dont le nom n'est pas précisé52, ou encore "Jehannin des Aloyz le Jeune, contrerolleur du grenier a seel de Vernon», qui indique sobrement: «Escript soubz mon seel et seing manuel $»^{53}$. Mais l'habitude n'est pas prise pour autant: une seule occurrence de ce type pour l'année $1378^{54}$ puis à nouveau trois mentions en $1379^{55}$, aucune enfin pour les neuf premiers mois de 1380 (graphique) ${ }^{56}$. Là encore, la proportion globale est révélatrice, puisque la signature n'est annoncée que dans 1,44\% (quinze mentions en tout et pour tout pour 1042 documents au total entre 1364 et 1380$)^{57}$. L'annonce de la signature dans la formule de corroboration sera beaucoup plus fréquente dès le début du règne de Charles VI pour se généraliser progressivement autour de 1400 .

Dans la quinzaine de cas recensés, le sceau est toujours annoncé avant la signature qui, même si elle est de plus en plus fréquente et tend véritablement à se généraliser, est (encore) l'auxiliaire du sceau dont elle s'émancipera au XV' siècle.

47. Paris, BnF, ms fr. 26010, $\mathrm{n}^{\circ} 1175$, quittance du 12 avril 1371.

48. Paris, BnF, ms fr. 26011, $\mathrm{n}^{\circ}$ 1330, quittance du 4 septembre 1372.

49. Paris, BnF, ms fr. 26012, $n^{\circ} 1495$, quittance du 16 juin 1374.

50. «En tesmoing de ce nous avons mis a ces lettres notre propre seel et signe manuel et a greigneur confirmacion a notre requeste y a esté mis le seel des obligacions de la viconté de Montrevillier » (Paris, BnF, ms fr. 26013, $\mathrm{n}^{\circ} 1833$, quittance du 14 décembre 1376).

51. «Tesmoing mon seel et sing manuel mis a ces presentes" (Paris, BnF, ms fr. 26013, $\mathrm{n}^{\circ}$ 1912, quittance du 24 avril 1377)

52. «Escript a Harefleu soubz le signet dudit grenier et mon seing manuel de moi contrerolleur» (Paris, BnF, ms fr. 26014, $\mathrm{n}^{\circ}$ 1998, quittance du 28 août 1377).

53. Paris, BnF, ms fr. 26014, $\mathrm{n}^{\circ}$ 2007, quittance du 15 septembre 1377.

54. Quittance passée par Jean Stancon, receveur général de la province de Rouen : «En tesmoing de ce j'ay seellé ceste lettre de mon seel et signe manuel» (Paris, BnF, ms fr. 26014, $\mathrm{n}^{\circ}$ 2198, 20 mai 1378).

55. Quittance passée pas Henri de Mante, «naguere viconte et receveur d'Avranche» : «n tesmoing de ce j'ay mis a ceste quittance mon propre seel et signée de ma main» (Paris, BnF, ms fr. 26015, $\mathrm{n}^{\circ}$ 2408, 27 janvier 1379). Acte du "Grenetier et contrerolleur du grenier a sel establi a Harefleu», qui fait écrire: «Escript a Harefleu soubz le signet dudit grenetier et le seing manuel de moy contrerolleur» (Paris, BnF, ms fr; 26016, $\mathrm{n}^{\circ}$ 2504, 2 juin 1379). Quittance passée en propre par Robinet Garnier, clerc de Jehan Stancon, receveur en la province de Rouen des aides ordonnées pour la guerre ( Tesmoing mon seel et signe manuel mis a ces presentes», Paris, BnF, ms fr. 26016, $\mathrm{n}^{\circ}$ 2560, 2 septembre 1379).

56. Charles V meurt le 16 septembre 1380.

57. Le corpus déjà modeste de mentions a conduit à les prendre toutes en considération et à ne pas retenir que les formules apposées par des tabellions ou leurs clercs. 
Les différentes formules sont révélatrices de la pratique de validation et donc de la perception de ce signe graphique. L'évolution des termes, de «signet» à «seing manuel», conforte cette analyse en faveur d'une assimilation, discrète, mais résolue, de la signature. Le nombre de mentions par année est un bon indicateur de la place croissante de la signature dans le dispositif de validation et donc de sa valeur probatoire, de plus en plus souvent requise, recherchée, d'où sa généralisation progressive. La signature participe davantage du dispositif de validation des actes, et en particulier ici des quittances; de signe périphérique, dont l'apposition est laissée à l'appréciation de l'autorité juridique émettrice ou des parties prenantes de l'acte, elle gagne progressivement une place essentielle, formant avec le sceau un dispositif complexe d'authentification, associant à sa valeur probatoire une puissante dimension symbolique.

\section{Conclusion}

Les tabellions des juridictions royales en Normandie sont incontestablement influencés par la chancellerie royale lorsqu'il leur faut adopter un paraphe, qui est tout à la fois leur marque personnelle et un signe d'appartenance à l'administration royale tout entière, sous l'autorité et au profit de laquelle ils instrumentent. L'originalité dont font preuve certains de ces praticiens de l'écrit est à prendre en considération, car il ne s'agit pas d'une pratique ponctuelle, anecdotique, produit de quelques tabellions fantaisistes. Nombreux sont en effet les tabellions qui jouent avec les possibilités graphiques, combinent, inventent, bref ont une approche ludique de ce signe graphique, qui participe de son essence au même titre que sa dimension symbolique - s'éloigner du paraphe type de chancellerie mais pas trop - ou alors, dans certains cas, prendre résolument un parti contraire, ce qui revient toujours à se déterminer par rapport au modèle original. Qu'ils se conforment à l'usage de l'administration royale (la proximité géographique et politique entre la Normandie et la capitale joue à plein) - cours souveraines, officiers, chancelleries et autres officines qui produisent les actes du pouvoir souverain - ou à l'opposé qu'ils s'en démarquent, les tabellions s'influencent aussi entre eux, faisant preuve d'un mimétisme parfois très poussé, ou encore jouant tout en subtilité avec les nuances, les variantes possibles, d'où une évidente impression de foisonnement qui témoigne du dynamisme de la juridiction gracieuse du roi dans la province normande.

Les tabellions sont d'actifs promoteurs de l'administration de Charles V dont ils produisent, diffusent les actes dans la province. Le seing manuel, et plus particulièrement le paraphe dont ils usent, participe de la mise en forme des documents. Le paraphe s'impose peu à peu pendant le règne de Charles $\mathrm{V}$ pour se généraliser sous Charles VI, devenant un élément incontournable d'une quittance établie par la juridiction gracieuse royale, attendu par les parties au même titre que le sceau. D’élément périphérique, de «satellite», la signature deviendra bientôt signe de validation à part entière et les tabellions qui, pendant le règne de Charles $\mathrm{V}$, ne signent pas par choix y viendront rapidement. Les juridictions qui instrumentent jouent un rôle essentiel dans 
l'organisation sociale par l'élaboration d'actes de tous ordres (même s'il est presque exclusivement question de quittance ici). Afin de déployer l'autorité royale et d'assurer leur propre légitimité sur leur territoire, elles utilisent tous les moyens à leur disposition, dont le sceau fleurdelisé - et la signature, emblème à part entière. Ce faisant, elles contribuent forcément (et les tabellions avec elles), à l'échelle de toute la province, au rayonnement du pouvoir royal dont les manifestations visibles se trouvent ainsi démultipliées.

\section{Bibliographie}

BARABÉ, Alexandre, Recherches historiques sur le tabellionage royal, principalement en Normandie et sur les divers modes de contracter à l'époque du Moyen Âge d'après de nombreuses pièces M. SS. et sigillographie normande en XXIV planches (183 sceaux) avec le fac-similé d'une belle charte ducale du XI siècle commentée par Dom Tassin en 1758 en deux lettres inédites, Rouen, H. Boissell, 1863.

BRETTHAUER, Isabelle, «Des hommes, des écrits, des pratiques, systèmes de production et marchés de l'écrit aux confins de la Normandie et du Maine à la fin du Moyen Âge», thèse en histoire médiévale, Université Paris 7, sous la direction de Mathieu ArNoux, $2011 \mathrm{a}$.

BRetTHAUer, Isabelle, «Acte et registres du tabellionage ancien d'Alençon (13521404) », dans Tabellions et tabellionages... Tabellions et tabellionages de la France médiévale et moderne, M. ARnoux et O. GuYotJeAnnin (dir.), Paris, École des chartes (Mémoires et documents, 90), 2011b, p. 252-277.

Tabellionages au Moyen Âge en Normandie: un notariat à découvrir, J.-L. RocH (dir.), Mont-Saint-Aignan, Presses universitaires de Rouen et du Havre, 2014, DOI: 10.400o/books.purh.1467.

JeAY, Claude, «Les seings manuels des tabellions (Normandie, XIVe-XVe siècles): signes personnels ou expression du pouvoir royal?», dans Tabellions et tabellionages de la France médiévale et moderne, M. Arnoux et O. Guyotjeannin (dir.), Paris, École des chartes (Mémoires et documents, 90), 2011, p. 325-348. 
Annexes

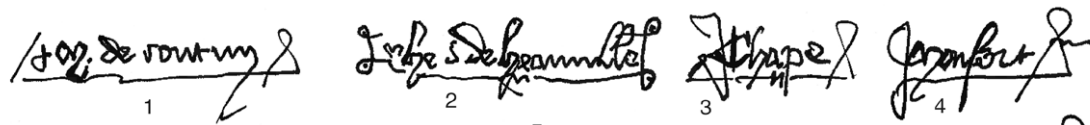

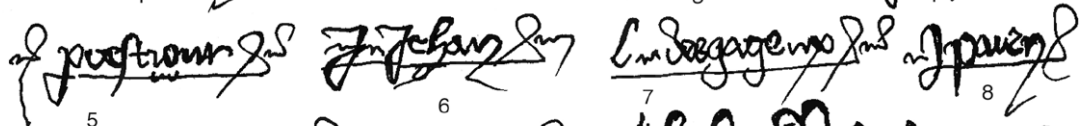

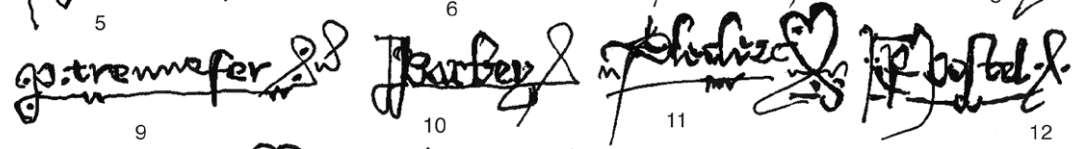

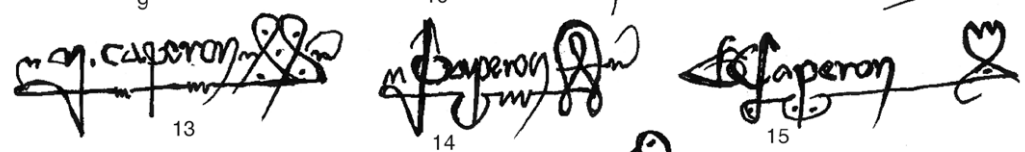

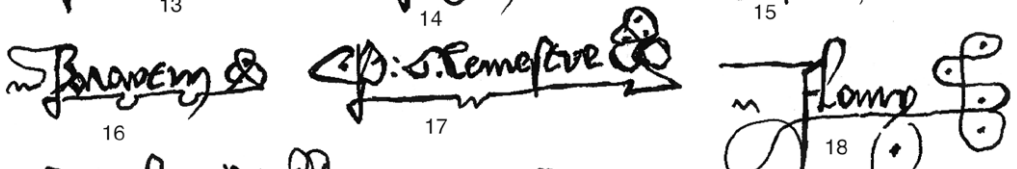

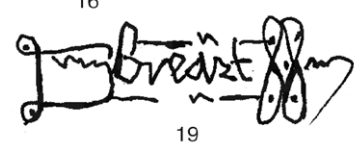
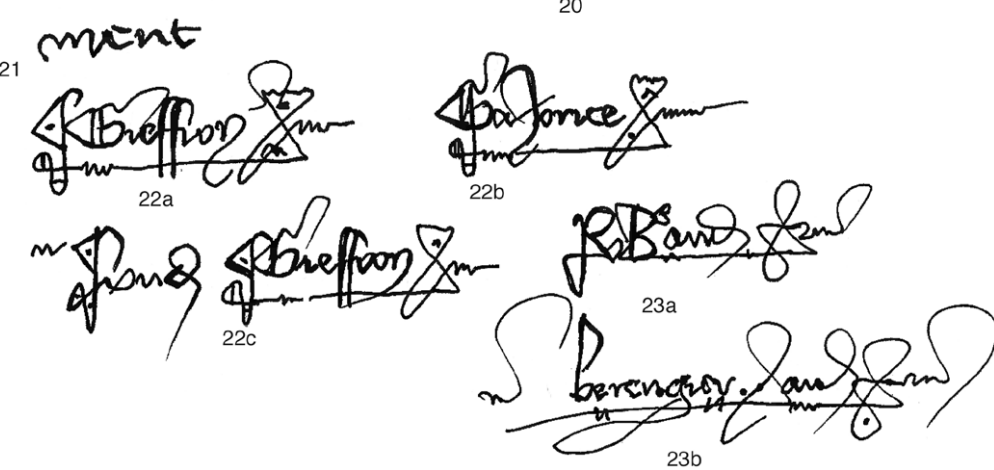

Annexe 1-Planche des seings 


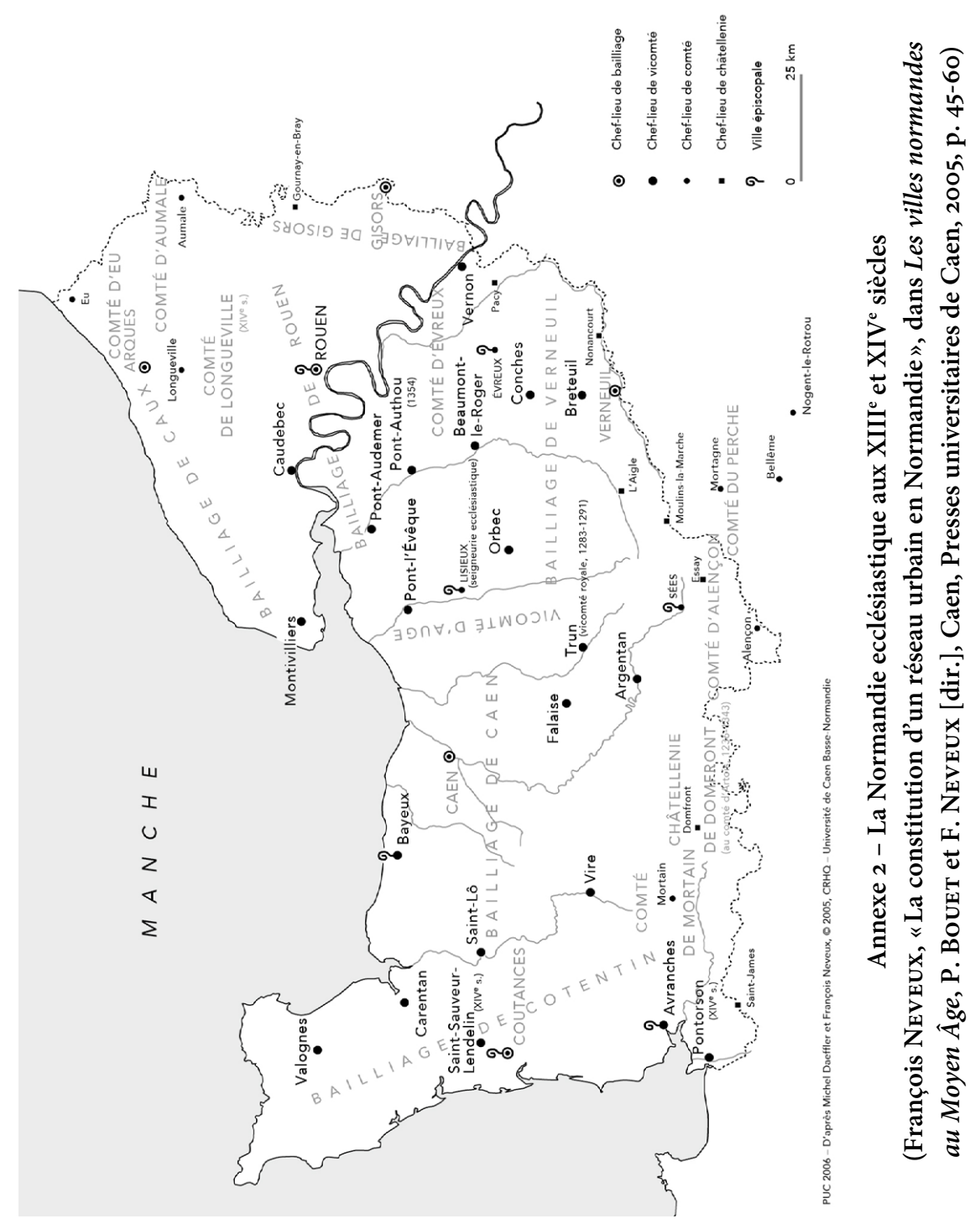

URL: http://journals.openedition.org/tabularia/4796 | DOI : 10.4000/tabularia.4796 


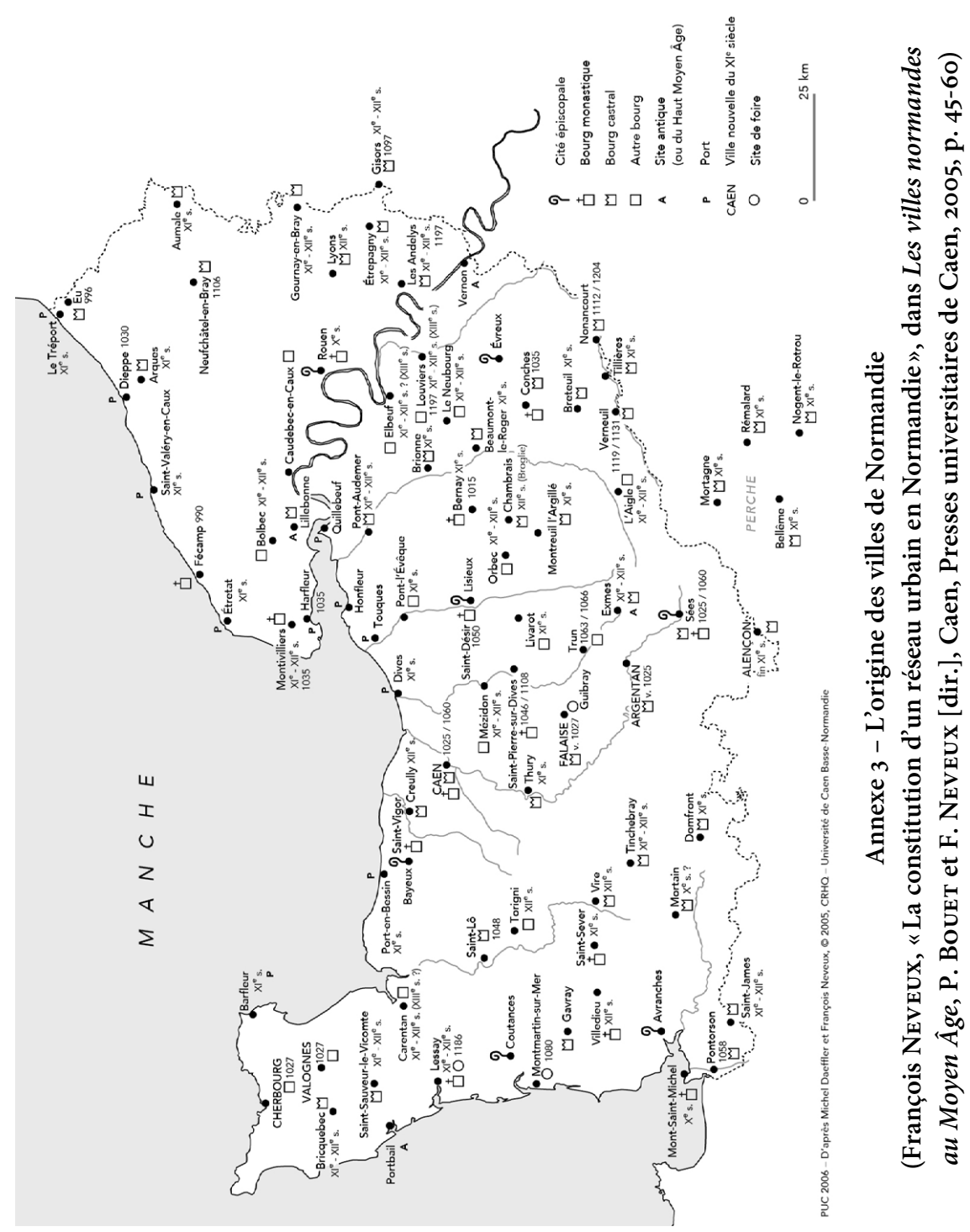




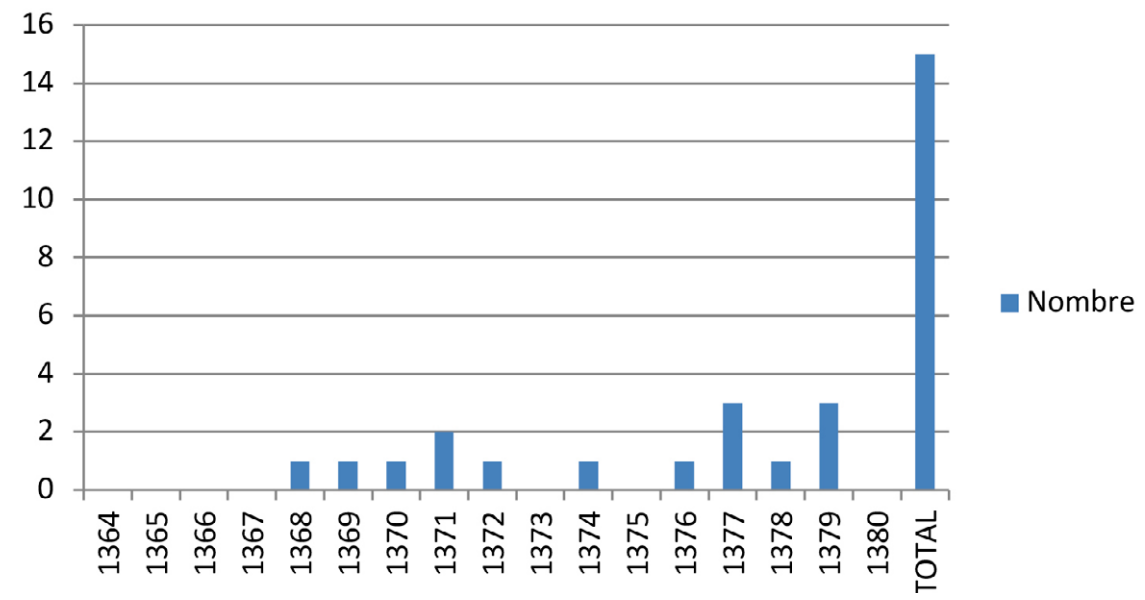

Annexe 4 - Mentions du seing manuel dans la formule de corroboration 


\begin{tabular}{|c|c|c|c|c|}
\hline $\begin{array}{l}\text { Nom } \\
\text { du tabellion }\end{array}$ & $\begin{array}{l}\text { Lieu } \\
\text { d'exercice }\end{array}$ & $\begin{array}{l}\text { Nombre } \\
\text { d'occur- } \\
\text { rences }\end{array}$ & $\begin{array}{l}\text { Premier } \\
\text { contreseing }\end{array}$ & $\begin{array}{l}\text { Dernier } \\
\text { contreseing }\end{array}$ \\
\hline $\begin{array}{l}\text { Amador } \\
\text { (Thomas) }\end{array}$ & $\begin{array}{l}\text { Tabellion de } \\
\text { la vicomté de } \\
\text { Pont-Authou au } \\
\text { siège de Lisieux }\end{array}$ & 1 & $\begin{array}{l}15 \text { septembre } \\
1380, \text { Paris, BnF, } \\
\text { ms fr. } 26016, \\
n^{\circ} 2744\end{array}$ & I \\
\hline Bacon (Johan) & $\begin{array}{l}\text { Tabellion de } \\
\text { la vicomté de } \\
\text { Rouen }\end{array}$ & 32 & $\begin{array}{l}28 \text { septembre } \\
\text { 1374, Paris, BnF, } \\
\text { ms fr. } 26012, \\
n^{0} 1525\end{array}$ & $\begin{array}{l}8 \text { septembre } \\
\text { 1379, Paris, BnF, } \\
\text { ms fr. } 26016 \text {, } \\
n^{\circ} 2571\end{array}$ \\
\hline $\begin{array}{l}\text { Barbé } \\
\text { (Jehan le) }\end{array}$ & $\begin{array}{l}\text { Tabellion de } \\
\text { la vicomté de } \\
\text { Bayeux }\end{array}$ & 1 & $\begin{array}{l}2 \text { juin } 1369, \\
\text { Paris, BnF, } \\
\text { ms fr. } 26008 \text {, } \\
n^{\circ} 699\end{array}$ & 1 \\
\hline $\begin{array}{l}\text { Barbey } \\
\text { (Guillaume le) }\end{array}$ & $\begin{array}{l}\text { Tabellion de } \\
\text { la vicomté de } \\
\text { Bayeux }\end{array}$ & 2 & $\begin{array}{l}17 \text { novembre } \\
1375 \text {, Paris, BnF, } \\
\text { ms fr. } 26012 \\
n^{\circ} 1718\end{array}$ & $\begin{array}{l}27 \text { juin } 1379 \text {, } \\
\text { Paris, BnF, } \\
\text { ms fr. } 26016 \text {, } \\
n^{0} 2515\end{array}$ \\
\hline Basille (Bertin) & $\begin{array}{l}\text { Tabellion de } \\
\text { la vicomté du } \\
\text { Pont-de-l'Arche }\end{array}$ & 1 & $\begin{array}{l}28 \text { janvier } 1368, \\
\text { Paris, BnF, } \\
\text { ms fr. } 26007, \\
n^{\circ} 462\end{array}$ & I \\
\hline Basset (Jehan) & $\begin{array}{l}\text { Tabellion } \\
\text { d'Exmes }\end{array}$ & 4 & $\begin{array}{l}30 \text { août } 1368, \\
\text { Paris, BnF, } \\
\text { ms fr. } 26008, \\
n^{0} 551\end{array}$ & $\begin{array}{l}10 \text { mars } 1371, \\
\text { Paris, BnF, } \\
\text { ms fr. } 26010 \text {, } \\
n^{\circ} 1148\end{array}$ \\
\hline $\begin{array}{l}\text { Baudet } \\
\text { (Symon) }\end{array}$ & $\begin{array}{l}\text { Tabellion de la } \\
\text { châtellenie de } \\
\text { Gournay }\end{array}$ & 2 & $\begin{array}{l}8 \text { juillet } 1370 \text {, } \\
\text { Paris, BnF, } \\
\text { ms fr. } 26009 \text {, } \\
n^{0} 929\end{array}$ & $\begin{array}{l}9 \text { novembre } \\
1371 \text {, Paris, BnF, } \\
\text { ms fr. } 26010, \\
n^{\circ} 1256\end{array}$ \\
\hline $\begin{array}{l}\text { Beaureperre } \\
\text { (Johan de) }\end{array}$ & $\begin{array}{l}\text { Tabellion de } \\
\text { la vicomté } \\
\text { d'Avranches }\end{array}$ & 1 & $\begin{array}{l}15 \text { octobre } 1377, \\
\text { Paris, BnF, } \\
\text { ms fr. } 26014, \\
n^{\circ} 2033\end{array}$ & l \\
\hline $\begin{array}{l}\text { Berengier } \\
\text { (Robert) }\end{array}$ & $\begin{array}{l}\text { Tabellion à } \\
\text { la vicomté de } \\
\text { Caen }\end{array}$ & 28 & $\begin{array}{l}17 \text { novembre } \\
1372, \mathrm{BnF} \\
\text { ms fr. } 26011, \\
n^{\circ} 1350\end{array}$ & $\begin{array}{l}17 \text { août } 1379, \\
\text { Paris, BnF, } \\
\text { ms fr. } 26016 \text {, } \\
n^{\circ} 2554\end{array}$ \\
\hline $\begin{array}{l}\text { Biaurain } \\
\text { (Pierre de) }\end{array}$ & $\begin{array}{l}\text { Tabellion de } \\
\text { la vicomté } \\
\text { d'Arches }\end{array}$ & 7 & $\begin{array}{l}8 \text { décembre } \\
\text { 1367, Paris, BnF, } \\
\text { ms fr. } 26007 \\
n^{\circ} 438\end{array}$ & $\begin{array}{l}7 \text { mai } 1368, \mathrm{BnF} \text {, } \\
\text { ms fr. } 26008, \\
n^{\circ} 500\end{array}$ \\
\hline
\end{tabular}




\begin{tabular}{|c|c|c|c|c|}
\hline $\begin{array}{l}\text { Bistrebec } \\
\text { (Robert de) }\end{array}$ & $\begin{array}{l}\text { Tabellion de la } \\
\text { vicomté d'Auge } \\
\text { au siège de } \\
\text { Dozulé }\end{array}$ & 1 & $\begin{array}{l}13 \text { août } 1378, \\
\text { Paris, BnF, } \\
\text { ms fr. } 26015 \text {, } \\
n^{\circ} 2249\end{array}$ & 1 \\
\hline $\begin{array}{l}\text { Bonnin l'Aîné } \\
\text { (Jehan) }\end{array}$ & $\begin{array}{l}\text { Tabellion de la } \\
\text { châtellenie de } \\
\text { Mantes }\end{array}$ & 23 & $\begin{array}{l}26 \text { novembre } \\
1365, \text { Paris, BnF, } \\
\text { ms fr. } 26006, \\
n^{\circ} 240\end{array}$ & $\begin{array}{l}4 \text { février } 1380 \text {, } \\
\text { Paris, BnF, } \\
\text { ms fr. } 26016 \text {, } \\
\mathrm{n}^{\circ} 2641\end{array}$ \\
\hline $\begin{array}{l}\text { Boue } \\
\text { (Enguerran } \\
\text { de la) }\end{array}$ & $\begin{array}{l}\text { Tabellion de la } \\
\text { châtellenie de } \\
\text { Chaumont }\end{array}$ & 3 & $\begin{array}{l}2 \text { mai } 1374, \\
\text { Paris, BnF, } \\
\text { ms fr. } 26012 \text {, } \\
n^{\circ} 1481\end{array}$ & $\begin{array}{l}16 \text { octobre } 1374 \text {, } \\
\text { Paris, BnF, } \\
\text { ms fr. } 26012, \\
n^{\circ} 1536\end{array}$ \\
\hline $\begin{array}{l}\text { Boullengier } \\
\text { (Robert le) }\end{array}$ & $\begin{array}{l}\text { Tabellion de } \\
\text { la vicomté de } \\
\text { Conches }\end{array}$ & 4 & $\begin{array}{l}27 \text { février } 1379 \text {, } \\
\text { Paris, BnF, } \\
\text { ms fr. } 26015, \\
n^{\circ} 2428\end{array}$ & $\begin{array}{l}1^{\mathrm{er}} \text { mars } 1379, \\
\text { Paris, BnF, } \\
\text { ms fr. } 26015, \\
\mathrm{n}^{\circ} 2436\end{array}$ \\
\hline $\begin{array}{l}\text { Bourdon } \\
\text { (Michel) }\end{array}$ & $\begin{array}{l}\text { Tabellion de } \\
\text { la vicomté de } \\
\text { Caudebec }\end{array}$ & 1 & $\begin{array}{l}9 \text { novembre } 1378 \text {, } \\
\text { Paris, } \mathrm{BnF} \text {, } \\
\text { ms fr. } 26015 \\
\mathrm{n}^{\circ} 2320\end{array}$ & 1 \\
\hline $\begin{array}{l}\text { Breart } \\
\text { (Guillaume) }\end{array}$ & $\begin{array}{l}\text { Clerc de la } \\
\text { vicomté de } \\
\text { Montivilliers }\end{array}$ & 6 & $\begin{array}{l}2 \text { août } 1377 \text {, } \\
\text { Paris, BnF, } \\
\text { ms fr. } 26014 \text {, } \\
n^{\circ} 1983\end{array}$ & $\begin{array}{l}26 \text { juin } 1380 \text {, } \\
\text { Paris, BnF, } \\
\text { ms fr. } 26016 \text {, } \\
n^{\circ} 2700\end{array}$ \\
\hline $\begin{array}{l}\text { Caperon } \\
\text { (Guiot) }\end{array}$ & $\begin{array}{l}\text { Tabellion de } \\
\text { la vicomté de } \\
\text { Coutances } \\
\text { au siège de } \\
\text { Montebourg }\end{array}$ & 1 & $\begin{array}{l}6 \text { mars } 1379 \\
\text { ms fr. } 26015 \\
n^{\circ} 2438\end{array}$ & 1 \\
\hline $\begin{array}{l}\text { Caperon } \\
\text { (Manessier) }\end{array}$ & $\begin{array}{l}\text { Tabellion de } \\
\text { la vicomté de } \\
\text { Neufchâtel-en- } \\
\text { Bray pour la } \\
\text { reine Blanche }\end{array}$ & 2 & $\begin{array}{l}16 \text { juin } 1377 \text {, } \\
\text { Paris, BnF, } \\
\text { ms fr. } 26014 \text {, } \\
n^{\circ} 1946\end{array}$ & $\begin{array}{l}5 \text { septembre } \\
1380, \\
\text { Paris, BnF, } \\
\text { ms fr. } 26016 \text {, } \\
\mathrm{n}^{\circ} 2736\end{array}$ \\
\hline $\begin{array}{l}\text { Caperon } \\
\text { (Rogier) }\end{array}$ & $\begin{array}{l}\text { Tabellion } \\
\text { auprès du garde } \\
\text { du sceau des } \\
\text { obligations de la } \\
\text { ville de Dieppe }\end{array}$ & 1 & $\begin{array}{l}18 \text { janvier } 1379 \text {, } \\
\text { Paris, BnF, } \\
\text { ms fr. } 26015 \text {, } \\
n^{\circ} 2403\end{array}$ & 1 \\
\hline $\begin{array}{l}\text { Chapenière } \\
\text { (Jehan de la) }\end{array}$ & $\begin{array}{l}\text { Tabellion de } \\
\text { la vicomté de } \\
\text { Bayeux }\end{array}$ & 1 & $\begin{array}{l}3 \text { novembre } \\
1365, \text { Paris, BnF, } \\
\text { ms fr. 26006, } \\
\mathrm{n}^{\circ} 225\end{array}$ & 1 \\
\hline
\end{tabular}




\begin{tabular}{|c|c|c|c|c|}
\hline $\begin{array}{l}\text { Chapillart } \\
\text { (Laurens) }\end{array}$ & $\begin{array}{l}\text { Clerc à la } \\
\text { vicomté de } \\
\text { Rouen }\end{array}$ & 10 & $\begin{array}{l}12 \text { avril } 1369, \\
\text { Paris, BnF, } \\
\text { ms fr. } 26008, \\
n^{\circ} 670\end{array}$ & $\begin{array}{l}17 \text { août } 1371 \text {, } \\
\text { Paris, BnF, } \\
\text { ms fr. } 26010 \text {, } \\
n^{\circ} 1236\end{array}$ \\
\hline $\begin{array}{l}\text { Courcaon } \\
\text { (Jaquet de) }\end{array}$ & $\begin{array}{l}\text { Tabellion de } \\
\text { la prévôté de } \\
\text { Vernon }\end{array}$ & 1 & $\begin{array}{l}18 \text { janvier } 1378, \\
\text { Paris, } \mathrm{BnF} \text {, } \\
\text { ms fr. } 26014, \\
\mathrm{n}^{\circ} 2105\end{array}$ & I \\
\hline $\begin{array}{l}\text { Coutun } \\
\text { (Michel de) }\end{array}$ & $\begin{array}{l}\text { Tabellion de } \\
\text { la vicomté de } \\
\text { Bayeux }\end{array}$ & 27 & $\begin{array}{l}3 \text { mai } 1364, \\
\text { Paris, BnF, } \\
\text { ms fr. } 26006, \\
n^{\circ} 9\end{array}$ & $\begin{array}{l}27 \text { août } 1374, \\
\text { Paris, BnF, } \\
\text { ms fr. } 26012 \text {, } \\
n^{\circ} 1519\end{array}$ \\
\hline $\begin{array}{l}\text { Descageux } \\
\text { (Laurent) }\end{array}$ & $\begin{array}{l}\text { Tabellion de la } \\
\text { vicomté de Vire }\end{array}$ & 1 & $\begin{array}{l}7 \text { octobre } 1367, \\
\text { Paris, BnF, } \\
\text { ms fr. } 26007 \text {, } \\
n^{\circ} 413\end{array}$ & I \\
\hline $\begin{array}{l}\text { Dyonise } \\
\text { (Jehan) }\end{array}$ & $\begin{array}{l}\text { Tabellion de } \\
\text { la vicomté du } \\
\text { Pont-de-l'Arche }\end{array}$ & 2 & $\begin{array}{l}11 \text { avril } 1372, \\
\text { Paris, BnF, } \\
\text { ms fr. } 26011 \text {, } \\
\mathrm{n}^{\circ} 1310\end{array}$ & $\begin{array}{l}1^{\mathrm{er}} \text { mai } 1378, \\
\text { Paris, BnF, } \\
\text { ms fr. } 26014 \text {, } \\
\mathrm{n}^{\circ} 2177\end{array}$ \\
\hline $\begin{array}{l}\text { Enguelos } \\
\text { (Guillaume) }\end{array}$ & $\begin{array}{l}\text { Tabellion de } \\
\text { la vicomté de } \\
\text { Longueville }\end{array}$ & 1 & $\begin{array}{l}4 \text { avril } 1380 \text {, } \\
\text { Paris, BnF, } \\
\text { ms fr. } 26016 \text {, } \\
n^{0} 2675\end{array}$ & I \\
\hline $\begin{array}{l}\text { Ernoul } \\
\text { (Thomas) }\end{array}$ & $\begin{array}{l}\text { Tabellion de } \\
\text { la vicomté de } \\
\text { Pont-de-l'Arche }\end{array}$ & 1 & $\begin{array}{l}1^{\mathrm{er}} \text { avril } 1371, \\
\text { Paris, BnF, } \\
\text { ms fr. } 26010 \text {, } \\
\mathrm{n}^{\mathrm{o}} 1162\end{array}$ & I \\
\hline Esber (Pierre) & $\begin{array}{l}\text { Tabellion de } \\
\text { la vicomté de } \\
\text { Saint-Sauveur- } \\
\text { le-Vicomte }\end{array}$ & 1 & $\begin{array}{l}25 \text { juillet } 1379 \text {, } \\
\text { Paris, } \mathrm{BnF} \text {, } \\
\text { ms fr. } 26016 \text {, } \\
\mathrm{n}^{\circ} 2542\end{array}$ & I \\
\hline $\begin{array}{l}\text { Evesque } \\
\text { (Jehan l') }\end{array}$ & $\begin{array}{l}\text { Tabellion de } \\
\text { la vicomté de } \\
\text { Bayeux }\end{array}$ & 1 & $\begin{array}{l}2 \text { septembre } \\
\text { 1370, Paris, BnF, } \\
\text { ms fr. } 26009 \text {, } \\
n^{\circ} 951\end{array}$ & I \\
\hline $\begin{array}{l}\text { Feron } \\
\text { (Gieffroy) }\end{array}$ & $\begin{array}{l}\text { Tabellion de } \\
\text { la vicomté de } \\
\text { Coutances } \\
\text { pour le roi de } \\
\text { Navarre }\end{array}$ & 2 & $\begin{array}{l}29 \text { novembre } \\
1368, \text { Paris, BnF, } \\
\text { ms fr. } 26008, \\
n^{\circ} 598\end{array}$ & $\begin{array}{l}17 \text { mars } 1373 \text {, } \\
\text { Paris, BnF, } \\
\text { ms fr. } 26011 \text {, } \\
\mathrm{n}^{\circ} 1379\end{array}$ \\
\hline
\end{tabular}




\begin{tabular}{|c|c|c|c|c|}
\hline Floury (Jehan) & $\begin{array}{l}\text { Tabellion de } \\
\text { la vicomté de } \\
\text { Beaumont-le- } \\
\text { Roger }\end{array}$ & 6 & $\begin{array}{l}20 \text { avril } 1368, \\
\text { Paris, BnF, } \\
\text { ms fr. } 26008, \\
n^{\circ} 491\end{array}$ & $\begin{array}{l}20 \text { avril } 1378, \\
\text { Paris, BnF, } \\
\text { ms fr. } 26014, \\
n^{\circ} 2172\end{array}$ \\
\hline $\begin{array}{l}\text { Galeren } \\
\text { (Guillaume) }\end{array}$ & $\begin{array}{l}\text { Tabellion juré } \\
\text { de la ville de } \\
\text { Caen }\end{array}$ & 1 & $\begin{array}{l}16 \text { mai } 1369, \\
\text { Paris, BnF, } \\
\text { ms fr. } 26008, \\
n^{\circ} 691\end{array}$ & l \\
\hline $\begin{array}{l}\text { Garmont } \\
\text { (Richard) }\end{array}$ & $\begin{array}{l}\text { Tabellion de } \\
\text { la vicomté } \\
\text { d'Avranches }\end{array}$ & 10 & $\begin{array}{l}6 \text { octobre } 1367 \text {, } \\
\text { Paris, BnF, } \\
\text { ms fr. } 26007 \text {, } \\
n^{\circ} 410\end{array}$ & $\begin{array}{l}26 \text { juillet } 1378 \text {, } \\
\text { Paris, } B n F, \\
\text { ms fr. } 26015 \text {, } \\
n^{\circ} 2233\end{array}$ \\
\hline $\begin{array}{l}\text { Gervaise } \\
\text { (Jehan) }\end{array}$ & $\begin{array}{l}\text { Clerc à la } \\
\text { vicomté de } \\
\text { Bayeux }\end{array}$ & 1 & $\begin{array}{l}8 \text { juillet } 1377 \text {, } \\
\text { Paris, BnF, } \\
\text { ms fr. } 26014, \\
n^{\circ} 1962\end{array}$ & l \\
\hline $\begin{array}{l}\text { Gillain } \\
\text { (Guillaume) }\end{array}$ & $\begin{array}{l}\text { Tabellion de } \\
\text { la vicomté } \\
\text { d'Orbec au siège } \\
\text { de Chambrais }\end{array}$ & 2 & $\begin{array}{l}13 \text { août } 1376, \\
\text { Paris, BnF, } \\
\text { ms fr. } 26013 \text {, } \\
n^{\circ} 1805\end{array}$ & $\begin{array}{l}3 \text { septembre } \\
1378, \text { Paris, BnF, } \\
\text { ms fr. } 26015, \\
n^{\circ} 2272\end{array}$ \\
\hline $\begin{array}{l}\text { Gourbaut } \\
\text { (Erart) }\end{array}$ & $\begin{array}{l}\text { Tabellion de la } \\
\text { châtellenie de } \\
\text { Gournay }\end{array}$ & 3 & $\begin{array}{l}12 \text { novembre } \\
\text { 1374, Paris, BnF, } \\
\text { ms fr. } 26012, \\
\mathrm{n}^{\circ} 1542, \\
3 \text { quittances du } \\
\text { même jour }\end{array}$ & I \\
\hline Grison (Jehan) & $\begin{array}{l}\text { Tabellion de } \\
\text { la vicomté de } \\
\text { Beaumont-le- } \\
\text { Roger }\end{array}$ & 2 & $\begin{array}{l}28 \text { février } 1370 \text {, } \\
\text { Paris, BnF, } \\
\text { ms fr. } 26009 \text {, } \\
\mathrm{n}^{\circ} 855\end{array}$ & $\begin{array}{l}5 \text { mars } 1370, \\
\text { Paris, BnF, } \\
\text { ms fr. } 26009 \text {, } \\
n^{\circ} 858\end{array}$ \\
\hline Guerout (Yon) & $\begin{array}{l}\text { Tabellion de } \\
\text { la vicomté de } \\
\text { Bayeux }\end{array}$ & 1 & $\begin{array}{l}2 \text { novembre } 1375, \\
\text { Paris, BnF, } \\
\text { ms fr. } 26012, \\
n^{\circ} 1705\end{array}$ & l \\
\hline $\begin{array}{l}\text { Guillart } \\
\text { (Colin le) }\end{array}$ & $\begin{array}{l}\text { Tabellion à } \\
\text { la vicomté de } \\
\text { Caen }\end{array}$ & 3 & $\begin{array}{l}14 \text { novembre } \\
\text { 1378, Paris, BnF, } \\
\text { ms fr. 26015, } \\
n^{\circ} 2332-2334, \\
3 \text { quittances } \\
\text { datées du même } \\
\text { jour }\end{array}$ & l \\
\hline
\end{tabular}




\begin{tabular}{|c|c|c|c|c|}
\hline Haiz (Colin) & $\begin{array}{l}\text { Tabellion de } \\
\text { la vicomté de } \\
\text { Carentan }\end{array}$ & 1 & $\begin{array}{l}15 \text { août } 1369, \\
\text { Paris, BnF, } \\
\text { ms fr. } 26008, \\
n^{\circ} 737\end{array}$ & I \\
\hline $\begin{array}{l}\text { Hauteville } \\
\text { (Raoul de) }\end{array}$ & $\begin{array}{l}\text { Tabellion de } \\
\text { la vicomté de } \\
\text { Pont-Authou }\end{array}$ & 6 & $\begin{array}{l}23 \text { juin } 1369 \text {, } \\
\text { Paris, BnF, } \\
\text { ms fr. } 26008 \text {, } \\
n^{0} 715\end{array}$ & $\begin{array}{l}28 \text { décembre } \\
1379, \text { Paris, } \mathrm{BnF}, \\
\mathrm{ms} \text { fr. } 26016, \\
\mathrm{n}^{\circ} 2623\end{array}$ \\
\hline $\begin{array}{l}\text { Heauville } \\
\text { (Eliot de) }\end{array}$ & $\begin{array}{l}\text { Tabellion de } \\
\text { la vicomté de } \\
\text { Valognes }\end{array}$ & 1 & $\begin{array}{l}14 \text { mai } 1365, \\
\text { Paris, BnF, } \\
\text { ms fr. } 26006 \text {, } \\
\mathrm{n}^{\circ} 168\end{array}$ & l \\
\hline $\begin{array}{l}\text { Hequet } \\
\text { (Raoul du) }\end{array}$ & $\begin{array}{l}\text { Tabellion de } \\
\text { la vicomté de } \\
\text { Saint-Sauveur- } \\
\text { le-Vicomte } \\
\end{array}$ & 7 & $\begin{array}{l}3 \text { juin } 1379 \text {, } \\
\text { Paris, BnF, } \\
\text { ms fr. } 26016 \text {, } \\
\mathrm{n}^{\circ} 2507\end{array}$ & $\begin{array}{l}16 \text { août } 1379 \text {, } \\
\text { Paris, BnF, } \\
\text { ms fr. } 26016 \text {, } \\
\mathrm{n}^{\circ} 2553\end{array}$ \\
\hline $\begin{array}{l}\text { Jaques } \\
\text { (Michiel) }\end{array}$ & $\begin{array}{l}\text { Tabellion de } \\
\text { la vicomté de } \\
\text { Bernay }\end{array}$ & 2 & $\begin{array}{l}18 \text { mai } 1375, \\
\text { Paris, BnF, } \\
\text { ms fr. } 26012 \text {, } \\
n^{\circ} 1616\end{array}$ & $\begin{array}{l}22 \text { mai } 1375, \\
\text { Paris, BnF, } \\
\text { ms fr. } 26012 \text {, } \\
\mathrm{n}^{\circ} 1618\end{array}$ \\
\hline Jehan (Johan) & $\begin{array}{l}\text { Tabellion de la } \\
\text { vicomté de Vire }\end{array}$ & 11 & $\begin{array}{l}31 \text { mai } 1364, \\
\text { Paris, BnF, } \\
\text { ms fr. } 26006 \text {, } \\
\mathrm{n}^{\circ} 16\end{array}$ & $\begin{array}{l}20 \text { avril } 1377, \\
\text { Paris, BnF, } \\
\text { ms fr. } 26013 \text {, } \\
n^{\circ} 1908\end{array}$ \\
\hline $\begin{array}{l}\text { Laingnel } \\
\text { (Pierre) }\end{array}$ & $\begin{array}{l}\text { Tabellion de } \\
\text { la vicomté de } \\
\text { Caen }\end{array}$ & 16 & $\begin{array}{l}12 \text { octobre } 1366 \text {, } \\
\text { Paris, BnF, } \\
\text { ms fr. } 26007, \\
n^{\circ} 315\end{array}$ & $\begin{array}{l}24 \text { septembre } \\
1368, \text { Paris, BnF, } \\
\text { ms fr. } 26008, \\
n^{\circ} 578\end{array}$ \\
\hline $\begin{array}{l}\text { Lenglois } \\
\text { (Guillaume) }\end{array}$ & $\begin{array}{l}\text { Tabellion de la } \\
\text { châtellenie de } \\
\text { Nogent-le-Roi }\end{array}$ & 2 & $\begin{array}{l}18 \text { mars } 1379, \\
\text { Paris, BnF, } \\
\text { ms fr. } 26015, \\
n^{\circ} 2447\end{array}$ & $\begin{array}{l}21 \text { mars } 1379, \\
\text { Paris, BnF, } \\
\text { ms fr. } 26015 \text {, } \\
n^{\circ} 2449\end{array}$ \\
\hline $\begin{array}{l}\text { Laucourt } \\
\text { (Jehan de) }\end{array}$ & $\begin{array}{l}\text { Clerc de la } \\
\text { vicomté de } \\
\text { Montivilliers }\end{array}$ & 14 & $\begin{array}{l}3 \text { juin } 1369 \text {, } \\
\text { Paris, BnF, } \\
\text { ms fr. } 26008 \text {, } \\
n^{\circ} 701\end{array}$ & $\begin{array}{l}22 \text { juillet } 1370 \text {, } \\
\text { Paris, BnF, } \\
\text { ms fr. } 26009 \text {, } \\
\mathrm{n}^{\circ} 934\end{array}$ \\
\hline $\begin{array}{l}\text { Lemestre } \\
\text { (Guillaume) }\end{array}$ & $\begin{array}{l}\text { Clerc à la } \\
\text { vicomté } \\
\text { d'Avranches }\end{array}$ & 1 & $\begin{array}{l}11 \text { novembre } \\
1378, \text { Paris, BnF, } \\
\text { ms fr. } 26015 \text {, } \\
n^{\circ} 2323\end{array}$ & l \\
\hline Lignis (Martin) & $\begin{array}{l}\text { Tabellion de } \\
\text { la vicomté } \\
\text { d'Avranches }\end{array}$ & 1 & $\begin{array}{l}11 \text { novembre } \\
\text { 1378, Paris, BnF, } \\
\text { ms fr. } 26015, \\
n^{\circ} 2323\end{array}$ & l \\
\hline
\end{tabular}




\begin{tabular}{|c|c|c|c|c|}
\hline Lon (Jehan de) & $\begin{array}{l}\text { Tabellion de } \\
\text { la vicomté de } \\
\text { Bayeux }\end{array}$ & 8 & $\begin{array}{l}14 \text { octobre } 1375, \\
\text { Paris, BnF, } \\
\text { ms fr. } 26012, \\
n^{\circ} 1692\end{array}$ & $\begin{array}{l}14 \text { mars } 1379 \\
\text { Paris, BnF, } \\
\text { ms fr. } 26015 \\
n^{\circ} 2444\end{array}$ \\
\hline $\begin{array}{l}\text { Longchamp } \\
\text { (Guillaume de) }\end{array}$ & $\begin{array}{l}\text { Tabellion et } \\
\text { garde du sceau } \\
\text { des obligations } \\
\text { de la châtellenie } \\
\text { de Gisors }\end{array}$ & 5 & $\begin{array}{l}22 \text { octobre } 1370 \text {, } \\
\text { Paris, BnF, } \\
\text { ms fr. } 26009 \\
n^{\circ} 982\end{array}$ & $\begin{array}{l}16 \text { mars } 1371, \\
\text { Paris, BnF, } \\
\text { ms fr. } 26010 \\
n^{\circ} 1151\end{array}$ \\
\hline $\begin{array}{l}\text { Malesche } \\
\text { (Denis) }\end{array}$ & $\begin{array}{l}\text { Tabellion de } \\
\text { la vicomté de } \\
\text { Breteuil }\end{array}$ & 1 & $\begin{array}{l}15 \text { décembre } \\
1376, \text { Paris, BnF, } \\
\text { ms fr. } 26013, \\
\mathrm{n}^{\circ} 1801\end{array}$ & 1 \\
\hline $\begin{array}{l}\text { Marchant } \\
\text { (Robert le) }\end{array}$ & $\begin{array}{l}\text { Tabellion de la } \\
\text { vicomté d'Auge } \\
\text { au siège de } \\
\text { Pont-l'Évêque }\end{array}$ & 1 & $\begin{array}{l}15 \text { mars } 1378, \\
\text { Paris, BnF, } \\
\text { ms fr. } 26014 \text {, } \\
n^{\circ} 2140\end{array}$ & l \\
\hline $\begin{array}{l}\text { Mareschal } \\
\text { (Jehan) }\end{array}$ & $\begin{array}{l}\text { Tabellion } \\
\text { auprès de } \\
\text { Robert Guillet } \\
\text { vicomte } \\
\text { d'Évreux }\end{array}$ & 1 & $\begin{array}{l}\text { mars } 1369 \text {, le } \\
\text { quantième } \\
\text { est illisible, } \\
\text { Paris, BnF, } \\
\text { ms fr. } 26008 \text {, } \\
n^{0} 626\end{array}$ & I \\
\hline Melin (Everart) & $\begin{array}{l}\text { Tabellion de } \\
\text { la vicomté de } \\
\text { Neufchâtel-en- } \\
\text { Bray }\end{array}$ & 1 & $\begin{array}{l}6 \text { juin } 1374, \\
\text { Paris, BnF, } \\
\text { ms fr. } 26012 \text {, } \\
n^{\circ} 1491\end{array}$ & I \\
\hline $\begin{array}{l}\text { Mendre } \\
\text { (Jourdain le) }\end{array}$ & $\begin{array}{l}\text { Tabellion de } \\
\text { la vicomté de } \\
\text { Montivilliers }\end{array}$ & 2 & $\begin{array}{l}2 \text { novembre } 1379 \text {, } \\
\text { Paris, BnF, } \\
\text { ms fr. } 26016 \\
n^{\circ} 2588\end{array}$ & $\begin{array}{l}14 \text { janvier } 1380 \text {, } \\
\text { Paris, } B n F, \\
\text { ms fr. } 26016 \text {, } \\
n^{\circ} 2631\end{array}$ \\
\hline Ment (Colin) & $\begin{array}{l}\text { Tabellion de la } \\
\text { vicomté d'Auge }\end{array}$ & 2 & $\begin{array}{l}3 \text { octobre } 1368, \\
\text { Paris, BnF, } \\
\text { ms fr. } 26008, \\
n^{\circ} 583\end{array}$ & $\begin{array}{l}4 \text { octobre } 1368 \text {, } \\
\text { Paris, BnF, } \\
\text { ms fr. } 26008, \\
n^{0} 586\end{array}$ \\
\hline $\begin{array}{l}\text { Meslin } \\
\text { (Guerart) }\end{array}$ & $\begin{array}{l}\text { Tabellion de } \\
\text { la vicomté de } \\
\text { Montivilliers }\end{array}$ & 1 & $\begin{array}{l}10 \text { novembre } \\
1378 \text {, Paris, BnF, } \\
\text { ms fr. } 26015, \\
n^{\circ} 2322\end{array}$ & l \\
\hline $\begin{array}{l}\text { Mesnil } \\
\text { (Guillemin du) }\end{array}$ & $\begin{array}{l}\text { Clerc de la } \\
\text { vicomté de } \\
\text { Montivilliers }\end{array}$ & 1 & $\begin{array}{l}26 \text { septembre } \\
1372 \text {, Paris, BnF, } \\
\text { ms fr. 26o11, } \\
\mathrm{n}^{\circ} 1335\end{array}$ & 1 \\
\hline
\end{tabular}




\begin{tabular}{|c|c|c|c|c|}
\hline $\begin{array}{l}\text { Mestre } \\
\text { (Nicolas le) }\end{array}$ & $\begin{array}{l}\text { Tabellion de } \\
\text { la vicomté de } \\
\text { Rouen }\end{array}$ & 48 & $\begin{array}{l}16 \text { février } 1365 \\
\text { Paris, } \mathrm{BnF} \text {, } \\
\text { ms fr. } 26006 \text {, } \\
\mathrm{n}^{\circ} 137\end{array}$ & $\begin{array}{l}19 \text { novembre } \\
1375, \text { Paris, BnF, } \\
\text { ms fr. } 26012, \\
n^{\circ} 1720\end{array}$ \\
\hline $\begin{array}{l}\text { Moigne } \\
\text { (Richart le) }\end{array}$ & $\begin{array}{l}\text { Tabellion de la } \\
\text { vicomté de Vire }\end{array}$ & 1 & $\begin{array}{l}3 \text { novembre } 1372 \text {, } \\
\text { Paris, BnF, } \\
\text { ms fr. } 26011, \\
n^{\circ} 1345\end{array}$ & I \\
\hline $\begin{array}{l}\text { Montfort } \\
\text { (Robert de) }\end{array}$ & $\begin{array}{l}\text { Tabellion à } \\
\text { Falaise }\end{array}$ & 24 & $\begin{array}{l}1^{\text {er }} \text { octobre } 1364, \\
\text { Paris, BnF, } \\
\text { ms fr. } 26006, \\
n^{\circ} 76\end{array}$ & $\begin{array}{l}13 \text { janvier } 1376, \\
\text { Paris, BnF, } \\
\text { ms fr. } 26013 \text {, } \\
\mathrm{n}^{\circ} 1757\end{array}$ \\
\hline $\begin{array}{l}\text { Montfort } \\
\text { (Guiot de) }\end{array}$ & $\begin{array}{l}\text { Tabellion de } \\
\text { la vicomté de } \\
\text { Falaise }\end{array}$ & 2 & $\begin{array}{l}27 \text { janvier } 1377, \\
\text { BnF, } \\
\text { ms fr. } 26013 \text {, } \\
n^{\circ} 1854\end{array}$ & $\begin{array}{l}21 \text { juillet } 1380 \text {, } \\
\text { BnF, } \\
\text { ms fr. } 26016 \text {, } \\
n^{\circ} 2712\end{array}$ \\
\hline $\begin{array}{l}\text { Morice } \\
\text { (Gieffroy) }\end{array}$ & $\begin{array}{l}\text { Tabellion de } \\
\text { la vicomté de } \\
\text { Caen }\end{array}$ & 5 & $\begin{array}{l}15 \text { décembre } \\
1364, \text { Paris, BnF, } \\
\text { ms fr. } 26006, \\
n^{\circ} 116\end{array}$ & $\begin{array}{l}22 \text { novembre } \\
1366, \\
\text { Paris, BnF, } \\
\text { ms fr. } 26007 \text {, } \\
\mathrm{n}^{\circ} 327\end{array}$ \\
\hline $\begin{array}{l}\text { Moyne } \\
\text { (Richart le) }\end{array}$ & $\begin{array}{l}\text { Tabellion de la } \\
\text { vicomté de Vire }\end{array}$ & 2 & $\begin{array}{l}22 \text { novembre } \\
\text { 1379, Paris, BnF, } \\
\text { ms fr. } 26016 \text {, } \\
n^{\circ} 2602-2603\end{array}$ & I \\
\hline Neel (Henry) & $\begin{array}{l}\text { Tabellion à } \\
\text { la vicomté de } \\
\text { Breteuil }\end{array}$ & 2 & $\begin{array}{l}12 \text { janvier } 1379 \text {, } \\
\text { Paris, BnF, } \\
\text { ms fr. } 26015 \text {, } \\
n^{\circ} 2394\end{array}$ & $\begin{array}{l}17 \text { janvier } 1379, \\
\text { Paris, BnF, } \\
\text { ms fr. } 26015 \\
n^{\circ} 2401\end{array}$ \\
\hline Paien (Raoul) & $\begin{array}{l}\text { Tabellion de } \\
\text { la vicomté de } \\
\text { Bayeux }\end{array}$ & 17 & $\begin{array}{l}13 \text { novembre } \\
1364 \text {, Paris, BnF, } \\
\text { ms fr. } 26006, \\
n^{\circ} 107\end{array}$ & $\begin{array}{l}8 \text { décembre } \\
1368, \text { Paris, BnF, } \\
\text { ms fr. } 26008, \\
n^{\circ} 600\end{array}$ \\
\hline Paillete (Raoul) & $\begin{array}{l}\text { Tabellion à } \\
\text { Évreux }\end{array}$ & 1 & $\begin{array}{l}15 \text { janvier } 1379 \text {, } \\
\text { Paris, BnF, } \\
\text { ms fr. } 26015 \text {, } \\
n^{\circ} 2399\end{array}$ & I \\
\hline $\begin{array}{l}\text { Peletier } \\
\text { (Gilles le) }\end{array}$ & $\begin{array}{l}\text { Tabellion de } \\
\text { la vicomté de } \\
\text { Pont-Authou }\end{array}$ & 1 & $\begin{array}{l}15 \text { mai } 1367, \\
\text { Paris, BnF, } \\
\text { ms fr. } 26007 \text {, } \\
n^{\circ} 381\end{array}$ & I \\
\hline
\end{tabular}




\begin{tabular}{|c|c|c|c|c|}
\hline $\begin{array}{l}\text { Pélichon } \\
\text { (Thomas) }\end{array}$ & $\begin{array}{l}\text { Tabellion de } \\
\text { la vicomté de } \\
\text { Caen }\end{array}$ & 44 & $\begin{array}{l}25 \text { novembre } \\
1364, \text { Paris, BnF, } \\
\text { ms fr. } 26006, \\
n^{\circ} 111\end{array}$ & $\begin{array}{l}15 \text { juin } 1375 \\
\text { Paris, BnF, } \\
\text { ms fr. } 26012 \text {, } \\
n^{\circ} 1634\end{array}$ \\
\hline Postel (Robert) & $\begin{array}{l}\text { Tabellion de } \\
\text { la vicomté du } \\
\text { Pont-de-l'Arche }\end{array}$ & 1 & $\begin{array}{l}7 \text { juin } 1377 \text {, } \\
\text { Paris, BnF, } \\
\text { ms fr. } 26014 \\
n^{\circ} 1941\end{array}$ & l \\
\hline $\begin{array}{l}\text { Precestiour } \\
\text { (Denis) }\end{array}$ & $\begin{array}{l}\text { Tabellion de } \\
\text { la vicomté de } \\
\text { Mortain }\end{array}$ & 1 & $\begin{array}{l}26 \text { avril } 1364, \\
\text { Paris, BnF, } \\
\text { ms fr. } 26006 \text {, } \\
n^{\circ} 8\end{array}$ & I \\
\hline $\begin{array}{l}\text { Prevost } \\
\text { (Guillaume le) }\end{array}$ & $\begin{array}{l}\text { Tabellion } \\
\text { auprès du } \\
\text { sénéchal de } \\
\text { Lisieux }\end{array}$ & 1 & $\begin{array}{l}1^{\text {er }} \text { octobre } 1368, \\
\text { Paris, BnF, } \\
\text { ms fr. } 26008, \\
n^{\circ} 582\end{array}$ & 1 \\
\hline $\begin{array}{l}\text { Prevosté } \\
\text { (Nicolas de la) }\end{array}$ & $\begin{array}{l}\text { Tabellion de } \\
\text { la prévôté de } \\
\text { Vernon }\end{array}$ & 1 & $\begin{array}{l}18 \text { octobre } 1369, \\
\text { Paris, BnF, } \\
\text { ms fr. } 26008 \\
n^{\circ} 773\end{array}$ & I \\
\hline $\begin{array}{l}\text { Prudomme } \\
\text { (Enguerran) }\end{array}$ & $\begin{array}{l}\text { Tabellion de la } \\
\text { vicomté d'Auge }\end{array}$ & 1 & $\begin{array}{l}\text { Quantième } \\
\text { et mois non } \\
\text { précisés, 1372, } \\
\text { Paris, BnF, } \\
\text { ms fr. 26o11, } \\
n^{0} 1313\end{array}$ & 1 \\
\hline $\begin{array}{l}\text { Quer } \\
\text { (Richard du) }\end{array}$ & $\begin{array}{l}\text { Tabellion de } \\
\text { la vicomté de } \\
\text { Coutances à } \\
\text { Saint-Lô }\end{array}$ & 1 & $\begin{array}{l}6 \text { octobre } 1368 \\
\text { Paris, BnF, } \\
\text { ms fr. } 26008 \\
n^{\circ} 590\end{array}$ & 1 \\
\hline $\begin{array}{l}\text { Raenieur } \\
\text { (Jehan) }\end{array}$ & $\begin{array}{l}\text { Tabellion de } \\
\text { la vicomté du } \\
\text { Pont-de-l'Arche }\end{array}$ & 2 & $\begin{array}{l}\text { Deux quittances } \\
\text { du } 10 \text { avril } 1365 \text {, } \\
\text { Paris, BnF, } \\
\text { ms fr. } 26006 \text {, } \\
n^{\circ} 154-155\end{array}$ & 1 \\
\hline $\begin{array}{l}\text { Riant } \\
\text { (Colart le) }\end{array}$ & $\begin{array}{l}\text { Tabellion } \\
\text { auprès du garde } \\
\text { du sceau des } \\
\text { obligations de la } \\
\text { ville de Dieppe }\end{array}$ & 2 & $\begin{array}{l}17 \text { avril } 1370 \text {, } \\
\text { Paris, BnF, } \\
\text { ms fr. } 26009 \text {, } \\
n^{\circ} 882\end{array}$ & $\begin{array}{l}28 \text { septembre } \\
1371 \text {, Paris, BnF, } \\
\text { ms fr. } 26010 \text {, } \\
\mathrm{n}^{\circ} 1241\end{array}$ \\
\hline $\begin{array}{l}\text { Rognon } \\
\text { (Jehan du) }\end{array}$ & $\begin{array}{l}\text { Clerc à la } \\
\text { vicomté de } \\
\text { Montivilliers }\end{array}$ & 2 & $\begin{array}{l}30 \text { août } 1378, \\
\text { Paris, BnF, } \\
\text { ms fr. } 26015 \text {, } \\
n^{\circ} 2269\end{array}$ & $\begin{array}{l}23 \text { février } 1379 \text {, } \\
\text { Paris, BnF, } \\
\text { ms fr. } 26015 \\
n^{0} 2425\end{array}$ \\
\hline
\end{tabular}




\begin{tabular}{|c|c|c|c|c|}
\hline Roux (Jehan le) & $\begin{array}{l}\text { Tabellion à } \\
\text { la vicomté de } \\
\text { Mortain }\end{array}$ & 5 & $\begin{array}{l}26 \text { août } 1378, \\
\text { Paris, BnF, } \\
\text { ms fr. } 26015, \\
n^{\circ} 2262\end{array}$ & $\begin{array}{l}28 \text { août } 1378, \\
\text { Paris, BnF, } \\
\text { ms fr. } 26015 \text {, } \\
n^{\circ} 2266\end{array}$ \\
\hline Roy (Colas le) & $\begin{array}{l}\text { Tabellion de } \\
\text { la vicomté de } \\
\text { Coutances à } \\
\text { Saint-Lô }\end{array}$ & 1 & $\begin{array}{l}4 \text { novembre } 1375 \text {, } \\
\text { Paris, BnF, } \\
\text { ms fr. } 26012 \text {, } \\
\mathrm{n}^{\circ} 1710\end{array}$ & I \\
\hline $\begin{array}{l}\text { Terrier } \\
\text { (Esber le) }\end{array}$ & $\begin{array}{l}\text { Tabellion de } \\
\text { la vicomté } \\
\text { d'Orbec }\end{array}$ & 25 & $\begin{array}{l}1^{\mathrm{er}} \text { avril } 1373 \\
\text { Paris, } \mathrm{BnF} \text {, } \\
\text { ms fr. } 26011, \\
\mathrm{n}^{\mathrm{o}} 1382\end{array}$ & $\begin{array}{l}3 \text { septembre } \\
1379, \text { Paris, BnF, } \\
\text { ms fr. } 26016, \\
n^{\circ} 2561\end{array}$ \\
\hline $\begin{array}{l}\text { Trennefer } \\
\text { (Perrin) }\end{array}$ & $\begin{array}{l}\text { Tabellion de } \\
\text { la vicomté de } \\
\text { Valognes }\end{array}$ & 1 & $\begin{array}{l}11 \text { septembre } \\
\text { 1366, Paris, BnF, } \\
\text { ms fr. } 26007 \text {, } \\
\mathrm{n}^{\circ} 308\end{array}$ & I \\
\hline $\begin{array}{l}\text { Troqueel } \\
\text { (Guillaume) }\end{array}$ & $\begin{array}{l}\text { Clerc à la } \\
\text { châtellenie des } \\
\text { Andelys }\end{array}$ & 8 & $\begin{array}{l}1^{\mathrm{er}} \text { avril } 1371, \\
\text { Paris, BnF, } \\
\text { ms fr. } 26010, \\
\mathrm{n}^{\circ} 1161\end{array}$ & $\begin{array}{l}25 \text { janvier } 1378, \\
\text { Paris, BnF, } \\
\text { ms fr. } 26014, \\
n^{\circ} 21093\end{array}$ \\
\hline $\begin{array}{l}\text { Valmellier } \\
\text { (Guillaume du) }\end{array}$ & $\begin{array}{l}\text { Clerc de } \\
\text { la vicomté } \\
\text { d'Arches }\end{array}$ & 2 & $\begin{array}{l}7 \text { février } 1368, \\
\text { Paris, BnF, } \\
\text { ms fr. } 26007, \\
n^{\circ} 465\end{array}$ & $\begin{array}{l}24 \text { mars } 1369, \\
\text { Paris, BnF, } \\
\text { ms fr. } 26008, \\
n^{\circ} 649\end{array}$ \\
\hline $\begin{array}{l}\text { Villons } \\
\text { (Benest le) }\end{array}$ & $\begin{array}{l}\text { Tabellion de } \\
\text { la vicomté de } \\
\text { Coutances }\end{array}$ & 2 & $\begin{array}{l}12 \text { novembre } \\
1375, \text { Paris, } \mathrm{BnF}, \\
\mathrm{ms} \text { fr. } 26012, \\
\mathrm{n}^{\circ} 1716\end{array}$ & $\begin{array}{l}11 \text { décembre } \\
\text { 1375, Paris, BnF, } \\
\text { ms fr. 26012, } \\
\mathrm{n}^{\circ} 1727\end{array}$ \\
\hline Waart (Jehan) & $\begin{array}{l}\text { Tabellion de } \\
\text { la vicomté } \\
\text { d'Arches }\end{array}$ & 21 & $\begin{array}{l}5 \text { décembre } 1368, \\
\text { Paris, BnF, } \\
\text { ms fr. } 26008, \\
n^{0} 599\end{array}$ & $\begin{array}{l}31 \text { août } 1380 \text {, } \\
\text { Paris, BnF, } \\
\text { ms fr. } 26016 \text {, } \\
n^{\circ} 2734\end{array}$ \\
\hline Wys (Jehan de) & $\begin{array}{l}\text { Tabellion de } \\
\text { la vicomté de } \\
\text { Rouen }\end{array}$ & 21 & $\begin{array}{l}4 \text { septembre } \\
1379, \text { Paris, } \mathrm{BnF}, \\
\mathrm{ms} \text { fr. } 26016 \\
\mathrm{n}^{\circ} 2566\end{array}$ & $\begin{array}{l}2 \text { août } 1380, \\
\text { Paris, BnF, } \\
\text { ms fr. } 26016 \text {, } \\
n^{\circ} 2723\end{array}$ \\
\hline Ys (Colin des) & $\begin{array}{l}\text { Tabellion } \\
\text { auprès du garde } \\
\text { du sceau des } \\
\text { obligations de la } \\
\text { ville de Dieppe }\end{array}$ & 1 & $\begin{array}{l}5 \text { février } 1365, \\
\text { Paris, BnF, } \\
\text { ms fr. } 26006 \text {, } \\
n^{\circ} 133\end{array}$ & I \\
\hline
\end{tabular}

Annexe 5 - Liste des tabellions normands sous le règne de Charles V, lieu, dates d'exercice et cotes extrêmes de leurs seings manuels 